\title{
Damage Detection Using a Graph-based Adaptive Threshold for Modal Strain Energy and Improved Water Strider Algorithm
}

\author{
Ali Kaveh ${ }^{1 *}$, Parmida Rahmani ${ }^{1}$, Armin Dadras Eslamlou ${ }^{1}$ \\ ${ }^{1}$ Centre of Excellence for Fundamental Studies in Structural Engineering, Iran University of Science and Technology, Tehran 13114- \\ 16846, Iran \\ * Corresponding author, e-mail: alikaveh@iust.ac.ir
}

Received: 21 January 2021, Accepted: 24 March 2021, Published online: 09 April 2021

\begin{abstract}
Damage detection through an inverse optimization problem has been investigated by many researchers. Recently, Modal Strain Energy (MSE) has been utilized as an index (MSEBI) for damage localization that serves to guide the optimization. This guided approach considerably reduces the computational cost and increases the accuracy of optimization. Although this index mostly exhibits an acceptable performance, it fails to find some damaged elements' locations in some cases. The aim of this paper is twofold. Firstly, a Graph-based Adaptive Threshold (GAT) is proposed to identify some of those elements that are not detected by basic MSEBI. GAT relies on the concepts from graph theory and MSE working as a simple anomaly detection technique. Secondly, an Improved version of the Water Strider Algorithm (IWSA) is introduced, applied to the damage detection problems with incomplete modal data and noisecontaminated inputs. Several optimization algorithms, including the newly-established Water Strider Algorithm (WSA), are utilized to test the proposed method. The investigations on several damage detection problems demonstrate the GAT and IWSA's satisfactory performance compared to the previous methods.
\end{abstract}

\section{Keywords}

structural damage detection, modal strain energy, graph-based adaptive threshold, improved Water Strider Algorithm

\section{Introduction}

Civil structures are prone to a variety of damages that stem from natural or artificial causes. For example, seismic ground motions, overloading, erosion, and temperature changes can cause minor or significant structural damages ranging from minor cracks to serious stability problems and failures. If we identify the damages and repair them before they get unrepairable, their adverse economic consequences, as well as fatalities and injuries, can be avoided [1].

Traditional visual inspection methods are expensive and time-consuming and become inaccurate or impractical when the inspected structure is vast and complicated. Even the local damage detection techniques such as radiography or ultrasonic methods are costly and challenging, especially in the mentioned structures. On the contrary, vibration-based techniques, so-called global methods, are more robust against the structures' size and complexity $[2,3]$. These techniques are upon the idea that sates when damages occur in a structure, its physical properties change and affect its vibrational characteristics such as mode shapes and frequencies [2]. Different methods have been developed to relate these changes to the location and/or severity of damages. These methods, based on the identified information, are categorized into four levels [4].

Level 1: Qualitative indication that damage might be present in the structure

Level 2: Potential location of damage in addition to Level 1

Level 3: Extent and severity of damage in addition to Levels 2

Level 4: Remaining service life and safety in addition to Levels 3

In the vibration-based inverse methods, an initial analytical model of the intact state of the studying structure is usually made. Afterward, the damage parameters are iteratively updated through an optimization process until the modal parameters comply with modal characteristics extracted from processing the damaged structure's measured vibration signal [5]. The obtained optimum solution represents the damage condition of the structure. 
This technique can detect damage information described in levels 1 to 3 . The underlying versatile and straightforward concept of this technique has made it widely popular among researchers. However, according to no free lunch theorem in search and optimization [6], there is no universal search strategy to outdo other methods in all problems; hence there is a compelling need to develop specific modern algorithms for such particular types of problems. In recent years, considerable studies have been conducted on different aspects of damage detection, such as the application of optimization metaheuristic algorithms as well as machine learning methods, efficient feature extraction, upgrading identification levels, and computational efficiency [7]. The traditional methods not only need a considerably long time to solve this optimization problem but also sometimes fail to converge to a near-global solution. For example, Li and Hong [8] indicated that a traditional gradient-based method involves almost $100 \%$ more computational time compared with new methods to process a model updating problem. As a result, in the following, some of the studies on applied metaheuristic algorithms for damage detection are reviewed.

Chou and Ghaboussi [9] applied the Genetic Algorithm (GA) to identify the damage location using the residual force and static displacements in structures. Boonlong [10] presented a Cooperative Coevolutionary Genetic Algorithm (CCGA) for vibration-based damage detection of a cantilever and supported beams. He considered random noise in the modal characteristics and indicated the superiority of the cooperative CCGA in comparison with standard GA. Majumdar et al. [11] employed Ant Colony Optimization (ACO) to optimize an objective function formulated based on natural frequencies to detect damage locations. Their investigations showed that the presented method is efficient for localization. Cha and Buyukozturk [12] proposed a framework using Modal Strain Energy (MSE) as an index to detect the location of multiple damages, and hybrid multi-objective GA, as the optimization algorithm. They used incomplete mode shapes and noise effects to show the robustness of the introduced framework. Tan et al. [13] utilized MSE in conjunction with Artificial Neural Networks and demonstrated this hybrid technique's effectiveness in damage detection of single and multipledamage scenarios of steel-concrete composite bridges. Kang et al. [14] proposed a hybrid version of Particle Swarm Optimization (PSO) combining with the Artificial Immune System algorithm. They showed that the proposed algorithm is robust and suitable for damage detection.
To lessen the computational load of the optimization process, Seyedpoor [15] introduced a two-stage method to reduce the number of optimization variables. He defined a Modal Strain Energy-Based Index (MSEBI) to eliminate the healthy elements from the optimization variables. This index associates positive and negative values to each element so that the positive values indicate prospective damage locations. In the second stage, he employed PSO to find the damage severities. Kaveh and Zolghadr [16] showed that the basic MSEBI, despite its strong performance, in some cases, cannot localize some of the damaged elements. Therefore, in the first stage, they randomly added extra elements through a stochastic process in the hope of including the damaged elements. Although their suggested method increases the chance of finding the undetected elements as optimization variables, it is evident that it also might be unable to capture the missed elements of the basic version. Also, it may drastically increase the number of variables.

In the present paper, the MSEBI is used to localize the damaged elements; however, the elements are selected considering an adaptive threshold. This threshold is formulated based on notions from graph theory, which performs like an anomaly detection algorithm. Moreover, an improved version of a new optimizer so-called Water Strider Algorithm (WSA), is developed to quantify the severity of damages in the second stage. These methods are evaluated in various numerical examples.

The rest of this paper is organized as follows: In Section 2, the nature-inspired WSA method, its improved version, and the objective function are explained. Section 3 presents the formulations regarding MSEBI and the proposed Graph-based Adaptive Threshold (GAT). The improved algorithm and suggested a graph-based anomaly detection method is investigated in Section 4, and finally, the concluding remarks are provided in Section 5.

\section{Optimization}

In this section, the optimization problem and the cost function are explained. Afterward, the standard WSA and its improved versions are described.

\subsection{Optimization problem}

As aforementioned, the presence of damage reduces the members' local stiffness, each of which is considered a finite element that constructs the whole structure. Therefore, a reduction in the local stiffness contributes to the global structural stiffness. In the inverse method, the 
damage of each element is defined as a continuous quantity $(d)$ that can vary between 0 and 1 . As explained in Eq. (1), 0 represents the intact state, 1 means the fully damaged condition, and the values between them determine the corresponding damage extent.

$k_{d}^{j}=\left(1-d^{j}\right) k_{h}^{j}$,

where, $k_{d}^{j}$ and $k_{h}^{j}$ are the local stiffness of damaged and healthy states of $j$ th element, respectively.

Since the modal characteristics of structures are related to the total stiffness and mass of structures, the damages cause variations in natural frequencies and mode shapes. To quantify the location and the severity of the damages, one can compare the modal characteristics of healthy and damaged states. Optimization algorithms, such as metaheuristics $[17,18]$, can be employed to minimize the differences between the analytical model's characteristics and those of the experiment. The optimization of $d$ variables determines the severity and location of the damaged elements. Thus, the damage detection problem can be defined as the following optimization problem

Given $\quad D^{T}=\left\{d^{1}, d^{2}, \ldots, d^{N E}\right\}$

Minimize $\quad f(D)$

Such that $\quad 0 \leq d^{i} \leq 1, i=1,2, \ldots, N E$

Where $f(D)$ denotes the objective function to be minimized, and $N E$ stands for the number of elements.

The objective function $f(D)$ can be defined based upon natural frequencies, mode shapes, or both. Different objective functions have been established and investigated in the literature $[11,19]$. The natural frequencies are highly prone to environmental effects such as temperature and trouble when studying symmetric structures. Yet, they are less likely to be contaminated with noise and can be extracted from a limited number of measurements. On the other hand, mode shapes are sensitive to noise and require a higher number of sensors compared to natural frequencies [20]. But it is noteworthy that mode shapes provide more information than frequencies and identify minor and local damage. It has been experienced that their combination provides us with more robust and accurate structural identifications [21]. Therefore, here the following function is considered for optimization

$f=\sum_{i=1}^{n}\left[w_{1}\left(\frac{f_{i}^{e}-f_{i}^{a}}{f_{i}^{a}}\right)^{2}+w_{2}\left(1-\frac{\left(\phi_{i}^{e T} \phi_{i}^{a}\right)^{2}}{\left(\phi_{i}^{e T} \phi_{i}^{e}\right)\left(\phi_{i}^{a T} \phi_{i}^{a}\right)}\right)\right], n=5$, where, $f_{i}^{e}$ and $f_{i}^{a}$ represent the $i$ th frequency of experimental and analytical models. $\phi_{i}^{e}$ and $\phi_{i}^{a}$ are the vectors representing mode shapes of the real structure and optimized model, respectively; the superscript $T$ means transpose; and the coefficients $w_{1}$ and $w_{2}$ are respectively assumed as 0.1 and 1 .

This optimization problem is always solvable because it is directly derived from the eigenvalue system related to the generalized equation of motion as follows:

$K \Phi=\Omega^{2} M \Phi$,

where $K$ is stiffness matrix, $M$ is the mass matrix, $\Phi$ includes the eigenvectors (free vibration modes) and $\Omega^{2}$ is a diagonal matrix of eigenvalues (free vibration frequencies squared) [22]. Therefore, the equilibrium of the system necessitates its solvability.

According to many previous studies in this field, the non-uniqueness problem can arise in model updating with insufficient data relative to the desired model complexity [23]. Herein, it is assumed that the changes in the mass matrix are negligible, the frequency and mode shape data for several modes are collected as input data, and all nonlinearities are omitted. Additionally, the results of examples are almost equal to what was defined as damage. Therefore, the data is sufficient for the uniqueness of the considered problems.

In practice, since all mode shapes and frequency may not be available, only the first five modes are taken into account. Besides, for realistically simulating the examples, the input modal properties are polluted with $1 \%$ random noise, as suggested in $[24,11]$. This objective function can be directly minimized using optimization algorithms without any preprocessing. But this process that is called a classic inverse method might be computationally expensive. Therefore, several techniques are developed that can reduce this computational load discussed in Section 3.

\subsection{Water Strider Algorithm}

WSA has been inspired by the life cycle of water strider insects [25]. This algorithm mimics their territorial life, ripple communication, mating process, foraging behavior, death, and succession. Kaveh and Dadras Eslamlou [25] thoroughly invested WSA and showed that it provides a suitable trade-off between exploration (i.e., exploring the new areas of search space) and exploitation (i.e., intensifying the search in the promising regions of search space). In the following, six main steps of the WSA are stated. 


\subsubsection{Birth}

In this step, the water striders (i.e., solutions) are randomly initialized in the lake (i.e., search space) as Eq. (5)

$\boldsymbol{W} \boldsymbol{S}_{\boldsymbol{i}}^{0}=\boldsymbol{L} \boldsymbol{b}+\boldsymbol{r a n d}_{\boldsymbol{i}} \cdot(\boldsymbol{U} \boldsymbol{b}-\boldsymbol{L} \boldsymbol{b}), i=1,2, \ldots, n w s$,

where, $\boldsymbol{W} \boldsymbol{S}_{\boldsymbol{i}}^{\mathbf{0}}$ denotes the initial position of $i$ th Water Strider (WS). $\boldsymbol{U} \boldsymbol{b}$ and $\boldsymbol{L} \boldsymbol{b}$ indicate the upper and lower bound vectors corresponding to variables' maximum and minimum allowable values, respectively; rand $_{\boldsymbol{i}}$ is a vector of uniform random numbers between 0 and 1 generated for the $W S_{i}$, and $n w s$ is the number of $W S_{s}$.

\subsubsection{Establishing territories}

In the second step, the solutions are divided into a predefined number of territories ( $n t)$ according to their ranks. As illustrated in Fig. 1, at first, the WSs are sorted based on their cost values and are placed in $\frac{n w s}{n t}$ groups then. Finally, they are selected based on their ranks in the groups and establish territories, as seen in Fig. 1.

\subsubsection{Mating process}

Each territory is usually occupied by a couple of female striders and one male strider, the 'keystone'. The main asset to the keystones is mating. In this step, he sends courtship calling ripples to a target female, and she responds by sending attraction or repulsive ripple signals. Regardless of the females' response, the male strider usually mounts the female, but she can prevent successful mating through unique mechanisms. The following equations are proposed to update the location of the keystone for either case

$$
\begin{cases}\boldsymbol{W} \boldsymbol{S}_{i}^{t+1}=\boldsymbol{W} \boldsymbol{S}_{i}^{t}+\boldsymbol{R}_{\boldsymbol{r a n d}} & \text { if mating happens } \\ \boldsymbol{W} \boldsymbol{S}_{i}^{t+1}=\boldsymbol{W} \boldsymbol{S}_{i}^{t}+\boldsymbol{R} \cdot\left(1+\boldsymbol{r a n d}_{i}\right) & \text { otherwise }\end{cases}
$$

where, $\boldsymbol{W} \boldsymbol{S}_{i}^{t}$ is the position of $i$ th WS in the $t$ th cycle, and rand $_{i}$ is the ith vector with random numbers between 0 and $1 . \boldsymbol{R}$ represents a vector that starts at the keystone's position $\left(\boldsymbol{W} \boldsymbol{S}_{i}^{t-1}\right)$ and ends at the position of the target female $\left(\boldsymbol{W} \boldsymbol{S}_{F}{ }^{t-1}\right)$. The target female is selected based on roulette wheel selection among the resident females of the same territory.

\subsubsection{Feeding process}

Unlike the males, the main asset to female WSs is food. Therefore, entomologists call them 'optimal foraging-habitat users', which means they usually occupy locations with the most food. After the mating process, the keystone
1. Sorting water striders

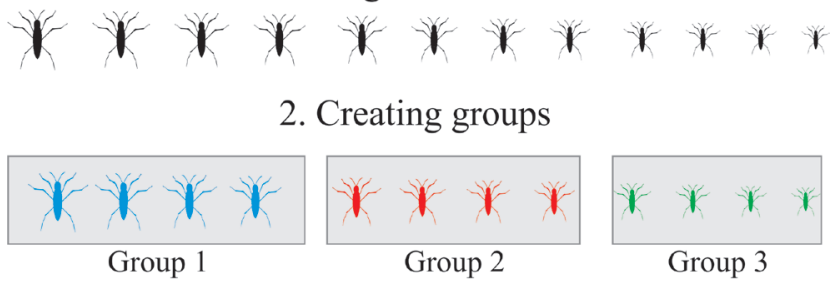

3. Establishing Territories

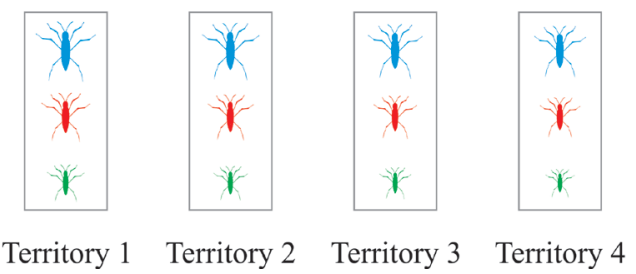

Fig. 1 A pictorial illustration of establishing territories

should recapture the expended energy. Hence, in this step, if the new location of the keystone updated in the mating process does not contain enough food, the keystone visits the territory with the most food, as Eq. (7).

$$
W S_{i}^{t+1}=W S_{i}^{t}+2 \operatorname{rand} .\left(W S_{B L}^{t}-W S_{i}^{t}\right),
$$

where, $\boldsymbol{W} \boldsymbol{S}_{\boldsymbol{B} L}{ }^{t}$ is the position of WS with the best cost value. It should be mentioned that the inability to improve the previous cost value is interpreted as a meaning that the WS couldn't find food.

\subsubsection{Death and succession}

Entering a new territory can be dangerous because the residents usually show aggressive territorial behaviors. Aggression between intruder and resident territorial is severe, and this fight may lead to murder. In this step, if the keystone cannot find enough food once more to increase his energy level, he is killed, and a new WS inside his territory is appointed to succeed as a new keystone, according to Eq. (8).

$$
\boldsymbol{W} \boldsymbol{S}_{i}^{t+1}=\boldsymbol{L} \boldsymbol{b}_{j}^{t}+2 \boldsymbol{r a n d}\left(\boldsymbol{U} \boldsymbol{b}_{j}^{t}-\boldsymbol{L} \boldsymbol{b}_{j}^{t}\right),
$$

where, $\boldsymbol{U} \boldsymbol{b}_{j}^{t}$ and $\boldsymbol{L} \boldsymbol{b}_{j}^{t}$ denote the maximum and minimum values of WSs' position inside $j$ th territory.

\subsubsection{Termination of algorithm}

Finally, if the termination condition is met, the algorithm stops to report the best position discovered so far. Otherwise, it will return to the mating step for a new loop. In this paper, the maximum number of structural analyses (MaxNSA) is considered the termination condition for a fair comparison. 
The pseudo-code of WSA is presented in Algorithm 1.

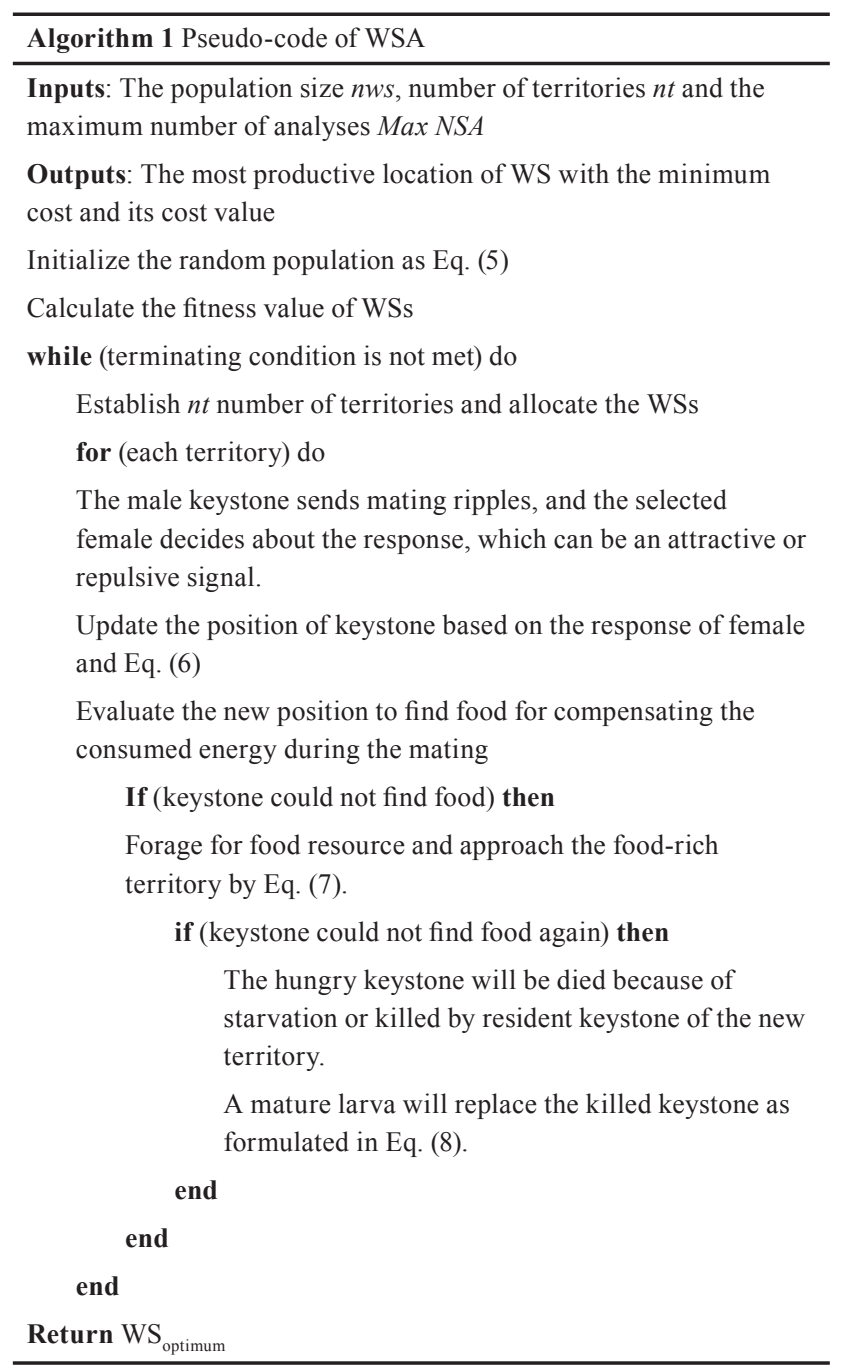

\subsection{Improved Water Strider Algorithm}

We investigated the updated position of WSs in the basic version and found that it ignores some spaces (neighbor regions) around the solutions. For example, as seen in Fig. 2 in a two-dimension problem, Eq. (6) puts the water striders in regions I or II and does not consider areas III and IV. In this paper, to cover the excluded areas, Eq. (6) is carried out for each dimension separately. This slight modification gives WSA the opportunity to discover the overlooked areas in the previous version. In Section 4, the performance of this version, as well as the basic versions and other algorithms, are investigated.

\section{Modal Strain Energy-based Index}

Assuming that damages change the local stiffness of the structure, its vibration and modal properties will be altered due to the following eigenproblem equation.

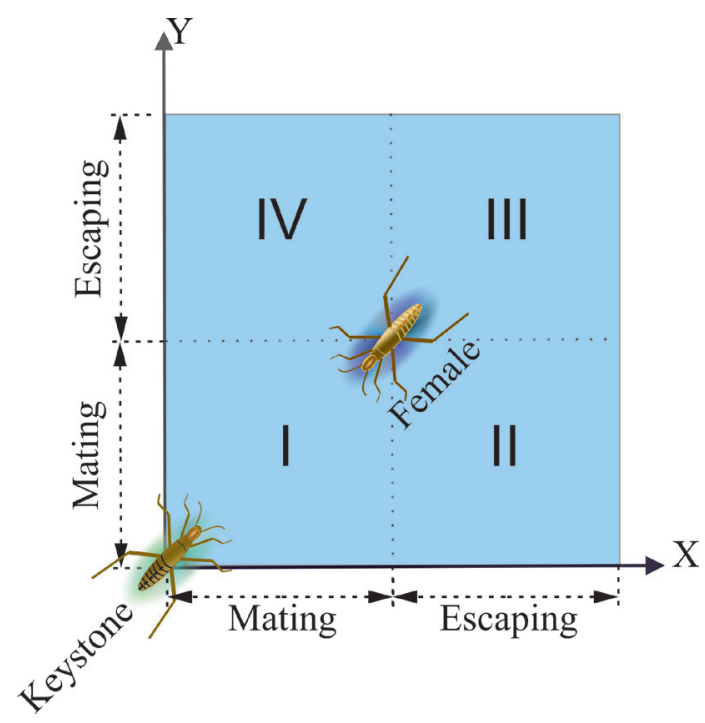

Fig. 2 Neighbor areas around the female WS

$\left[\boldsymbol{K}-\omega_{i}^{2} \boldsymbol{M}\right] \boldsymbol{\Phi}_{i}=0$

where, $\boldsymbol{K}$ and $\boldsymbol{M}$ are stiffness and mass matrices, and $\omega_{i}$ and $\boldsymbol{\Phi}_{i}$ denote the th circular frequency (eigenvalue) and mode shape (eigenvector) of structure, respectively.

An approximate localization of damages can be obtained by assessing the modal strain energy of a healthy structure and damaged structure as Eqs. (10) and (11).

$$
\begin{aligned}
& M S E_{i j}^{h}=\Phi_{i}^{j} k_{j} \Phi_{i}^{j}, \\
& M S E_{i j}^{d}=\Phi_{d i}^{j} k_{j} \Phi_{d i}^{j},
\end{aligned}
$$

where, $M S E_{i j}^{h}$ and $\boldsymbol{\Phi}_{i}^{j}$ denote the modal strain energy and mode shape of a healthy state of $j$ th element related to the $i$ th mode, respectively; $M S E_{i j}^{d}$ and $\boldsymbol{\Phi}_{d i}^{j}$ are those of the damaged state; and $k_{j}$ is the element stiffness of the $j$ th element.

To normalize the elements' modal strain energy, they are divided by the summation of the modal strain energy of all elements creating the structure as Eq. (12).

$$
n M S E_{i j}=\frac{M S E_{i j}}{\sum_{j=1}^{m} M S E_{i j}},
$$

where, $n M S E$ is the normalized modal strain energy, and $m$ is the total number of elements.

In practice, the identification of the higher modes become more complex and challenging. Thus, the normalized modal strain energy for $n$ number of first modes can be averagely calculated as follows

$m n M S E_{j}=\frac{\sum_{i=1}^{n} n M S E_{i j}}{n}$. 
Since damage reduces the corresponding element's local stiffness, it can be said that its displacement should be increased; therefore, the average modal strain energy of the damaged element generally should be higher than its healthy state. Seyedpoor [15] utilized this result to propose a two-stage method for damage identification. In which, at the first stage, the suspicious elements were localized according to the Eq. (14)

$$
\operatorname{MSEBI}_{j}=\max \left[0, \frac{m n M S E_{j}^{d}-m n M S E_{j}^{h}}{m n M S E_{j}^{h}}\right],
$$

where, $M S E B I_{j}$ denotes modal strain energy-based index, and $d$ and $h$ superscripts show the damaged and healthy states, respectively. When $M S E B I_{j}$ is nonzero, it shows that $m n M S E_{j}^{d}$ is higher than $m n M S E_{j}^{h}$, so the $j$ th element is a potential location for damage.

In the second stage, the determined locations are considered the variables of the optimization problem of damage detection, and the optimization is performed particularly on these variables. Although this methodology can lead to efficient damage detection, it suffers from a significant shortcoming. To be more specific, the fraction represented in Eq. (14) might exhibit negative values in some damaged elements; thus, the index misses the damaged elements and yields to an imprecise identification.

Kaveh and Zolghadr [16] suggested a stochastic technique to deal with this issue. Some of the undetermined elements at the first stage are randomly chosen in their method and are involved in the optimization process. This technique partly improves the accuracy of the previous two-stage method. However, since it relies on a stochastic selection, it is evident that it might miss some damaged elements.

An alternative graph-based anomaly detection algorithm is defined in the present paper, which can augment the selected elements at the first stage through an adaptive threshold. This algorithm is comprehensively detailed in the next sections.

\subsection{Basic definitions from the theory of graphs}

The topological features of structures can be easily simulated and analyzed by graphs [26]. In recent decades, some strict application of graph theory in structural engineering has been introduced, for example, they have been employed for swift structural analysis [27], finite element domain decomposition [28], structural optimization [29], damage detection [30], and sensor placement [31].
A mathematical introduction to graph theory would be excessive and unjustifiable at this point; thus, for the sake of brevity, in the following, just the most essential definitions and notions are provided. Throughout the paper, we consider simple undirected graphs.

Definition 1 A graph $G(V, E)$ is an ordered pair, where $V$ denotes a non-empty finite set whose elements are termed vertices, and $E$ is a set of edges connecting a subset of the pair of vertices.

Fig. 3. (a) illustrates a simple graph with 6 vertices and 8 edges.

Definition 2 Two vertices $u$ and $v$ are called adjacent if they are connected by an edge $e=(u, v)$.

For example, in Fig. 3. (a), vertices 1 and 2 are adjacent.

Definition 3 Two edges $e=(u, v)$ and $f=(w, v)$ are called the incident if they share a vertex $v$.

For instance, in Fig. 3. (a), edges $a$ and $b$ are incidents, for they share vertex 2 .

Definition 4 A sequence of vertices $P=\left(v_{1}, v_{2}, \ldots, v_{n}\right)$, in which for $1 \leq i<n, v_{i}$ is adjacent to $v_{i+1}$, is called a path of length $n-1$.

In Fig. 3.(a), $P=(1,2,3,5,6)$ represents a path of length 4.

Definition 5 Line graph of $G,(L(G))$, is a graph whose vertices represent the edges of $G$ and if these edges are incident in $G$, the corresponding vertices are adjacent in $L(G)$.

The line graph of graph $G$ is illustrated in Fig. 3. (b).

Definition 6 Distance matrix $(D)$ of a graph is a square matrix, in which each array $D_{i j}$ represents the length of the shortest path between vertices $v_{i}$ and $v_{j}$.

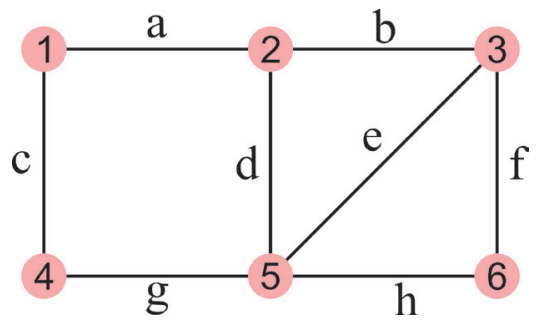

(a)

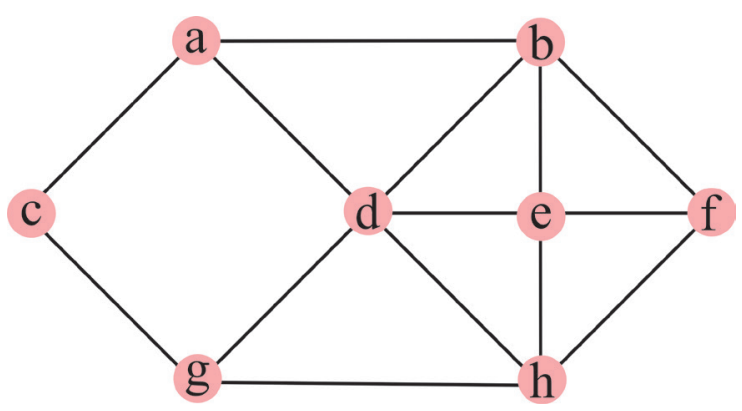

(b)

Fig. 3 Illustration of (a) graph $G$ and (b) its line graph $L(G)$ 
In this study, the "distance" function existing as an internal function in MATLAB is used, and it applies Dijkstra's algorithm, which has $O(V+E \log V)$ complexity for calculating the distance matrix. Where $V$ is vertices, and $E$ is the set of edges. Moreover, since calculating the Distance matrix for a structure is done only once before entering the optimization phase, it does not take a long time.

For example, in Fig. 3.(a), there are various paths between vertices 1 and 6 , but the shortest path that corresponds to their distance is of length 3 . Several algorithms have been proposed to find the shortest path between vertices, such as the Breadth-first search [32] and Dijkstra's algorithm [33].

\subsection{Proposed graph-based adaptive threshold (GAT)}

To remedy the defects of the two-stage MSE-based method [15], a graph-based anomaly detection algorithm is proposed to increase the number of suspicious elements. In the basic two-stage method, zero value is considered a constant threshold level, below which (i.e., elements with negative values of MSE) are ignored. To augment the set of suspicious elements and the previously detected elements, a threshold based on the MSEBI value of other elements and their graph-theoretic distance is defined to consider the situation of neighbor elements and include additional elements. Unlike the content threshold (i.e., zero) of the primary method, this threshold is adaptive to each element's condition. The whole process of the proposed framework is illustrated in Fig. 4. As seen, after calculating the $\overline{\boldsymbol{M S E B I}}$ that is redefined as Eq. (15), the threshold for each element is determined.

$$
\overline{M S E B I}_{j}=\frac{m n M S E_{j}^{d}-m n M S E_{j}^{h}}{m n M S E_{j}^{h}}
$$

In the following, the steps of this algorithm are explained.

Step 1: Representing the structure as a graph

Every structure can be divided into different members connected through linking nodes. If the structural members and nodes are considered edges and vertices, the structure can be modeled as a graph. In this step, according to the topological properties of the studying structure, a graph $(G)$ is associated with the structure.

\section{Step 2: Creating a line graph}

In the second step, the line graph $(L(G))$ of the underlying graph that was assembled in the first step is created.

Step 3: Calculating the distance matrix

Here, the distance matrix $(D)$ of the line graph is calculated. The estimated matrix must be an $m$-by- $m$ square matrix, where $m$ denotes the number of members in the studying structure.

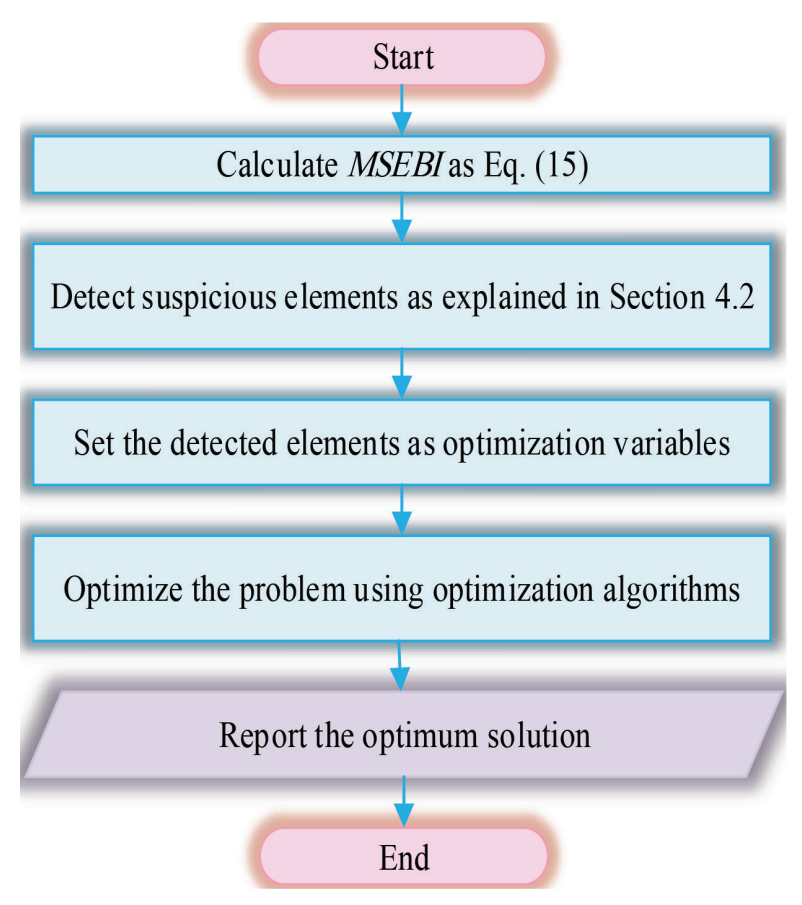

Fig. 4 Flowchart of the proposed framework

Step 4: Setting an adaptive threshold

In this step, without considering the positive arrays of $\overline{M S E B I}$ vector that already has been accepted as potential locations of damages, an adaptive threshold is defined to include some of the elements with negative $\overline{M S E B I}$. This threshold is set in such a way that it represents a weighted average of its neighbors' $\overline{M S E B I}$ and detects the abnormal items that possess higher $\overline{M S E B I}$ compared to their neighbors. For each node of the line graph, related to the members of the structure, the threshold $\left(T_{i}\right)$ is defined as Eq. (16)

$$
T_{i}=\frac{\sum_{j=1}^{m} e^{-d_{i j}} \cdot \overline{M S E B I}_{j}}{\sum_{j=1}^{m} e^{-d_{i j}}}, \quad i=1,2, \ldots, N E,
$$

where, $\overline{M S E B I}$ denotes the modal strain energy value of the $j$ th element with negative values; $N E$ stands for the number of elements, and $d_{i j}$ are the array in the $i$ th row and $j$ th column of distance $(D(L(G)))$ matrix.

Step 5: Detecting further suspicious elements

After calculating the threshold of the elements, elements with the $\overline{M S E B I}$ values above their corresponding thresholds are appended to the candidate elements.

To show GAT's capability in damage localization compared to the basic two-stage method and stochastic version, a ten-bar truss structure is considered, as shown in Fig. 5(a). In this structure, elements 4,6 , and 8 with respectively $50 \%, 5 \%$, and $50 \%$ damages are assumed to be damage scenarios. The $\overline{M S E B I}$ values are calculated and shown in Fig. 6.(a). As illustrated in Fig. 5, the line graph 


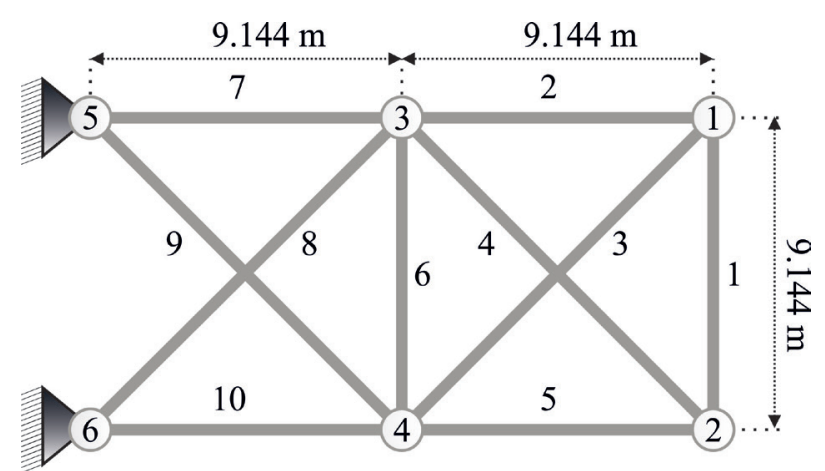

(a)

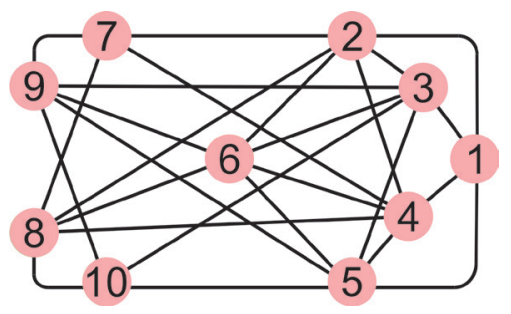

(b)

Fig. 5 A schematic of the truss structure and its line graph. (a) Ten-bar truss structure (b) Line graph of the truss structure

of the truss is determined, and the adaptive thresholds are calculated according to $\overline{M S E B I}$ and Eq. (16) In Fig. 6(a), the calculated adaptive threshold values are demonstrated with black lines. Fig. 6(b) shows the elements that are detected through the methodologies proposed in $[15,16]$, as well as the new approach. As seen, the suggested GAT can effectively detect a set of suspicious elements, including all damaged elements, while other approaches miss some of those elements. For instance, unlike the new method, both previous methods could not capture element 6 as a damaged bar. Although the new approach identified an extra element (i.e., bar 3), there is no concern about it. Because the optimizer will determine that the element is healthy, on the other side, if the methods miss some damaged elements, the optimizer cannot detect the element as damaged because there will not be any variable regarding those elements in the two-stage method.

\section{Numerical results}

In this section, the proposed methodology is investigated by testing three benchmarked numerical examples. For this purpose, two damage scenarios, with and without noise cases, and incomplete modal information for each case, are examined. The introduced IWSA, basic WSA [25], GA [34], PSO [35], ICA [36], MFO [37], GWO [38], NNA [39], CBO [40] and HHO [41] algorithms are utilized for optimization. Moreover, the general inverse damage detection method is also implemented to show the proposed

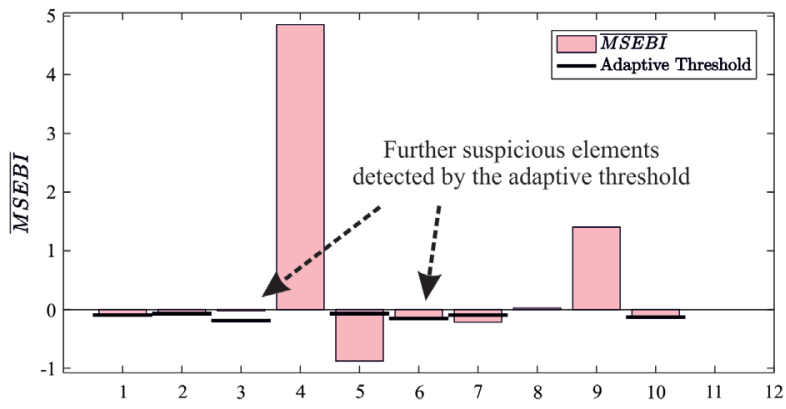

(a)

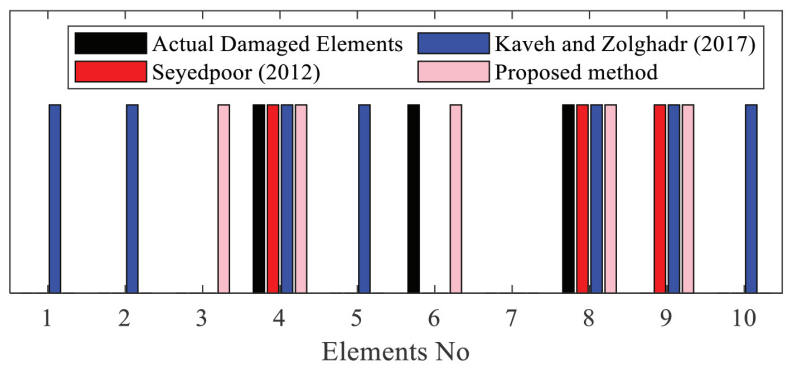

(b)

Fig. 6 An example of GAT and damage localization. (a) $\overline{M S E B I}$ values and GAT (b) Suspicious elements identified by different methods

methodology's efficiency. The internal parameter of algorithms is tuned according to the literature [39, 41, 42], as reported in Table 1. The maximum number of structural analyses (MaxNSA), as the termination condition, is set equal to 50000, and the number of populations is set to 50. These examples are programed in MATLAB R2016b software and processed in a computer with Intel ${ }^{\circledR}$ Core $^{\mathrm{TM}}$ i7_4510UCPU@v2.00 GHz processor and 8.00 GB RAM.

Table 1 Internal parameters of metaheuristic algorithms

\begin{tabular}{lcc}
\hline algorithm & parameter & value \\
\hline GA & beta & 8 \\
& $p_{c}$ & 0.8 \\
& $p_{m}$ & 0.3 \\
& $m u$ & 0.02 \\
PSO & gama & 0.1 \\
& $c_{1}, c_{2}$ & 2 \\
ICA & $w$ & 0.3 \\
& $N-$ Empire & $N p o p / 10$ \\
& $\gamma$ & $0.1 \mathrm{rad}$ \\
CBO & $\beta$ & 2 \\
GWO & $\xi$ & 0.1 \\
MFO & COR & {$[0,1]$} \\
NNA & $a$ & {$[0,2]$} \\
HHO & $a$ & {$[-2,-1]$} \\
\hline The and IWSA & - & 2 \\
\hline
\end{tabular}

${ }^{1}$ The coefficient of restitution (COR) 


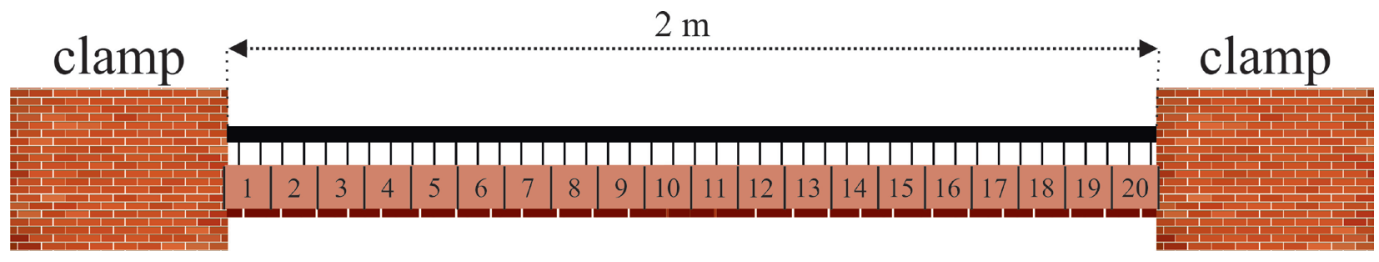

Fig. 7 A schematic of a 20-element bridge

\subsection{0-element clamped bridge}

As the first numerical example, ten optimization algorithms are applied to detect a clamped bridge's damage scenarios, divided into 20 elements, as shown in Fig 7. The length, height, and width of the beam are $2 \mathrm{~m}, 0.15 \mathrm{~m}$, and $0.15 \mathrm{~m}$, respectively. The modulus of elasticity and mass density are $68.9 \mathrm{GPa}$ and $2770 \mathrm{~kg} / \mathrm{m}^{3}$, respectively. Two damage scenarios are assessed, and the noise effects are considered according to Table 2 [16].

In the first scenario, the $\overline{M S E B I}$ value of elements 2 and 6 are the only positive values for this structure. The basic version is unable to detect element 12 as suspicious; thus, if we neglect members with negative MSEBI, this element would not be captured as a damaged element. However, the proposed GAT method suggests elements 2, 6, 8, 9, and 12 as damaged elements that contain all faulty elements in this scenario. Moreover, in the second scenario, the $\overline{M S E B I}$ value of elements $1,4,7$, and 16 are the only positive values for this structure and the $\overline{M S E B I}$ value of element 9 is negative; while, the proposed GAT suggests elements $1,3,4,7,9,11$, and 16 as damaged elements that cover all damaged elements.

The comparison among the examined optimization algorithms using the classic inverse method in terms of the average, Minimum (Min), and Standard Deviation (STD) results of the cost function values are provided in Table 3. The best results are written in bold font that is often obtained by the introduced IWSA and standard WSA. According to the results, the applied modification to WSA improves the outcomes, especially in the Noise-free case. Among other algorithms, the PSO obtained the minimum of the

Table 2 Damage scenarios for the bridge fixed support

\begin{tabular}{lcc}
\hline & Damaged elements & Damage severity \\
\hline Scenario \#1 & 2,6 , and 12 & $60 \%, 60 \%$ and $5 \%$ \\
Scenario \#2 & $1,7,9$, and 16 & $35 \%, 60 \%, 5 \%$ and $25 \%$ \\
\hline
\end{tabular}

Table 3 The results of the classic inverse method in the 20 -element bridge

\begin{tabular}{|c|c|c|c|c|c|c|c|}
\hline \multirow[t]{2}{*}{ Algorithm } & \multirow[t]{2}{*}{ Scenario } & \multicolumn{3}{|c|}{ Noise-free } & \multicolumn{3}{|c|}{ With-Noise } \\
\hline & & Average & Min & STD & Average & Min & STD \\
\hline \multirow[t]{2}{*}{ IWSA } & 1 & $1.44 E-09$ & $1.17 \mathrm{E}-15$ & $2.66 \mathrm{E}-09$ & 1.49E-04 & 1.49E-04 & $6.54 \mathrm{E}-09$ \\
\hline & 2 & 6.64E-09 & 2.57E-17 & $7.87 E-09$ & $1.55 E-04$ & $1.55 \mathrm{E}-04$ & 7.03E-08 \\
\hline \multirow[t]{2}{*}{ WSA } & 1 & $1.41 \mathrm{E}-08$ & $1.16 \mathrm{E}-16$ & $1.24 \mathrm{E}-08$ & $1.49 \mathrm{E}-04$ & $1.49 E-04$ & 2.17E-09 \\
\hline & 2 & $3.06 \mathrm{E}-08$ & $3.09 \mathrm{E}-11$ & $1.85 \mathrm{E}-08$ & $1.55 E-04$ & $1.55 \mathrm{E}-04$ & 7.02E-11 \\
\hline \multirow[t]{2}{*}{ PSO } & 1 & $3.44 \mathrm{E}-05$ & $7.65 \mathrm{E}-07$ & $9.20 \mathrm{E}-05$ & $1.65 \mathrm{E}-04$ & 1.49E-04 & $1.95 \mathrm{E}-05$ \\
\hline & 2 & $3.84 \mathrm{E}-05$ & 3.07E-07 & 7.11E-05 & $1.95 \mathrm{E}-04$ & $1.55 E-04$ & $9.83 \mathrm{E}-05$ \\
\hline \multirow[t]{2}{*}{ GA } & 1 & 0.0149 & $6.00 \mathrm{E}-03$ & $5.60 \mathrm{E}-03$ & $1.62 \mathrm{E}-02$ & 0.0097 & $5.00 \mathrm{E}-03$ \\
\hline & 2 & 0.0145 & $7.90 \mathrm{E}-03$ & $5.30 \mathrm{E}-03$ & $1.68 \mathrm{E}-02$ & 0.0084 & 0.0041 \\
\hline \multirow[t]{2}{*}{ ICA } & 1 & $5.41 \mathrm{E}-04$ & $1.13 \mathrm{E}-04$ & $3.73 \mathrm{E}-04$ & $1.10 \mathrm{E}-03$ & $3.05 \mathrm{E}-04$ & $1.10 \mathrm{E}-03$ \\
\hline & 2 & $6.52 \mathrm{E}-04$ & $1.52 \mathrm{E}-04$ & $3.60 \mathrm{E}-04$ & $1.00 \mathrm{E}-03$ & $2.15 \mathrm{E}-04$ & $6.10 \mathrm{E}-04$ \\
\hline \multirow[t]{2}{*}{ MFO } & 1 & $2.78 \mathrm{E}-05$ & $8.88 \mathrm{E}-16$ & $6.78 \mathrm{E}-05$ & $4.50 \mathrm{E}-03$ & $1.51 \mathrm{E}-04$ & $1.79 \mathrm{E}-02$ \\
\hline & 2 & $3.49 \mathrm{E}-05$ & $1.04 \mathrm{E}-16$ & 7.71E-05 & $6.21 \mathrm{E}-04$ & $1.58 \mathrm{E}-04$ & $1.80 \mathrm{E}-03$ \\
\hline \multirow[t]{2}{*}{ GWO } & 1 & $4.86 \mathrm{E}-05$ & $4.90 \mathrm{E}-06$ & $5.23 \mathrm{E}-05$ & $2.24 \mathrm{E}-04$ & $1.69 \mathrm{E}-04$ & $8.41 \mathrm{E}-05$ \\
\hline & 2 & $4.02 \mathrm{E}-04$ & $3.26 \mathrm{E}-05$ & $1.40 \mathrm{E}-03$ & $2.95 \mathrm{E}-04$ & 2.07E-04 & $6.56 \mathrm{E}-05$ \\
\hline \multirow[t]{2}{*}{ NNA } & 1 & $1.31 \mathrm{E}-05$ & $2.48 \mathrm{E}-09$ & $1.67 \mathrm{E}-05$ & 1.79E-04 & $1.49 \mathrm{E}-04$ & $5.70 \mathrm{E}-05$ \\
\hline & 2 & $2.00 \mathrm{E}-05$ & $1.25 \mathrm{E}-07$ & 2.17E-05 & $1.81 \mathrm{E}-04$ & $1.55 \mathrm{E}-04$ & $2.34 \mathrm{E}-05$ \\
\hline \multirow[t]{2}{*}{$\mathrm{CBO}$} & 1 & $1.53 \mathrm{E}-04$ & $1.54 \mathrm{E}-05$ & $9.08 \mathrm{E}-05$ & $2.34 \mathrm{E}-04$ & $1.72 \mathrm{E}-04$ & $5.87 \mathrm{E}-05$ \\
\hline & 2 & $1.41 \mathrm{E}-04$ & $3.40 \mathrm{E}-05$ & $6.78 \mathrm{E}-05$ & $3.09 \mathrm{E}-04$ & $1.84 \mathrm{E}-04$ & $1.12 \mathrm{E}-04$ \\
\hline \multirow[t]{2}{*}{ HHO } & 1 & 0.0494 & $2.64 \mathrm{E}-04$ & 0.0357 & 0.0299 & $1.68 \mathrm{E}-04$ & 0.0332 \\
\hline & 2 & 0.0334 & 0.0045 & 0.0304 & 0.0263 & 0.0043 & 0.0285 \\
\hline
\end{tabular}


with-noise case along with IWSA and WSA. Moreover, NNA stands in second place and shows an acceptable performance in some cases.

The performances of the examined optimization algorithms using the suggested GAT technique through the two-stage method are investigated in Table 4. As seen, the IWSA reaches the minimum mean for all cases. WSA and MFO in the noise-free cases of the first and second scenarios fall in the next places. $\mathrm{CBO}$ for the noise-free case of both scenarios is placed in the third rank. For noise-free scenarios, IWSA attains the best standard deviation, and MFO achieves both scenarios' best minimum.

According to Tables 3 and 4, the noise-contaminated inputs adversely affects the results and generally increases the cost values. Comparing the GAT results with those of the classic method shows that the cost values are significantly improved.

The average convergence curves of IWSA, WSA, and the best algorithm with the best mean are presented in Fig. 8. As shown, GAT expedites the process of optimization. Furthermore, IWSA and WSA have a higher convergence rate than the remained algorithms. Although in the with-noise condition of the second scenario, PSO has a higher convergence speed, it has been trapped in a local minimum that carries a higher cost.
The optimum results of the IWSA for classic and GAT methods and the actual damages are depicted in Fig. 9. As shown, both damage detection methods accurately predicted the damages in noise-free cases, but some elements are wrongly detected by the classic method in the withnoise cases. In the two-stage GAT, there is approximately no false detection. The results powerfully demonstrate the capability of the GAT for detecting damages in this bridge.

\subsection{Two-span continuous steel bridge}

In this example, the same algorithms are applied to detect the damages of a two-span continuous steel bridge, which is divided into 40 elements, as shown in Fig. 10. The length, height, and width of the beam are $8 \mathrm{~m}, 0.15 \mathrm{~m}$, and $0.15 \mathrm{~m}$, respectively. The modulus of elasticity and mass density are $210 \mathrm{GPa}$ and $7860 \mathrm{~kg} / \mathrm{m}^{3}$, respectively. Two damage scenarios are implemented, and the noise effects are considered according to Table 5 [16].

In the First scenario, both $\overline{M S E B I}$ and GAT detects whole damage elements. In the second scenario, the $\overline{M S E B I}$ values of elements 2, 6, 26, and 32 are positive, and this value for element 8 is negative; so the basic $\overline{M S E B I}$ is unable to capture this element as a damaged one; while, GAT nominates elements $1,2,6,8,21,26$, and 32 as suspicious elements that comprise all damage elements.

Table 4 Graph-based Adaptive Threshold for Modal Strain Energy in the two-stage method in the 20-element bridge

\begin{tabular}{|c|c|c|c|c|c|c|c|}
\hline \multirow[t]{2}{*}{ Algorithm } & \multirow[t]{2}{*}{ Scenario } & \multicolumn{3}{|c|}{ Noise-free } & \multicolumn{3}{|c|}{ With-Noise } \\
\hline & & Average & Min & STD & Average & Min & STD \\
\hline \multirow[t]{2}{*}{ IWSA } & 1 & $1.04 \mathrm{E}-21$ & $3.85 \mathrm{E}-24$ & $1.08 E-21$ & 1.49E-04 & $1.49 \mathrm{E}-04$ & 7.14E-09 \\
\hline & 2 & $2.79 \mathrm{E}-21$ & $7.76 \mathrm{E}-24$ & 4.57E-21 & $1.55 E-04$ & $1.55 \mathrm{E}-04$ & $1.65 \mathrm{E}-16$ \\
\hline \multirow[t]{2}{*}{ WSA } & 1 & $1.51 \mathrm{E}-20$ & $1.96 \mathrm{E}-23$ & $5.94 \mathrm{E}-20$ & $1.51 \mathrm{E}-04$ & $1.51 \mathrm{E}-04$ & $1.36 \mathrm{E}-16$ \\
\hline & 2 & $3.68 \mathrm{E}-19$ & $7.95 \mathrm{E}-22$ & $1.03 \mathrm{E}-18$ & $1.58 \mathrm{E}-04$ & $1.58 \mathrm{E}-04$ & $1.99 \mathrm{E}-16$ \\
\hline \multirow[t]{2}{*}{ PSO } & 1 & $5.51 \mathrm{E}-21$ & $4.66 \mathrm{E}-26$ & $7.67 \mathrm{E}-21$ & $1.71 \mathrm{E}-04$ & $1.71 \mathrm{E}-04$ & $1.42 \mathrm{E}-16$ \\
\hline & 2 & $4.45 \mathrm{E}-17$ & $6.76 \mathrm{E}-24$ & $1.95 \mathrm{E}-16$ & $1.79 \mathrm{E}-04$ & $1.79 \mathrm{E}-04$ & $1.03 \mathrm{E}-15$ \\
\hline \multirow[t]{2}{*}{ GA } & 1 & $1.34 \mathrm{E}-05$ & $9.49 \mathrm{E}-07$ & $1.69 \mathrm{E}-05$ & $2.02 \mathrm{E}-04$ & $1.74 \mathrm{E}-04$ & $2.88 \mathrm{E}-05$ \\
\hline & 2 & $2.26 \mathrm{E}-04$ & $5.77 \mathrm{E}-05$ & $1.43 \mathrm{E}-04$ & $4.31 \mathrm{E}-04$ & $2.29 \mathrm{E}-04$ & $1.46 \mathrm{E}-04$ \\
\hline \multirow[t]{2}{*}{ ICA } & 1 & $1.08 \mathrm{E}-19$ & $3.54 \mathrm{E}-23$ & $1.43 \mathrm{E}-19$ & $1.86 \mathrm{E}-04$ & $1.86 \mathrm{E}-04$ & $6.05 \mathrm{E}-16$ \\
\hline & 2 & $4.21 \mathrm{E}-16$ & $2.23 \mathrm{E}-21$ & $9.12 \mathrm{E}-16$ & $1.94 \mathrm{E}-04$ & $1.91 \mathrm{E}-04$ & $2.75 \mathrm{E}-06$ \\
\hline \multirow[t]{2}{*}{ MFO } & 1 & $2.29 \mathrm{E}-21$ & $9.38 E-25$ & $9.96 \mathrm{E}-21$ & $1.85 \mathrm{E}-04$ & $1.71 \mathrm{E}-04$ & $5.91 \mathrm{E}-05$ \\
\hline & 2 & $2.22 \mathrm{E}-05$ & $1.09 \mathrm{E}-25$ & $6.84 \mathrm{E}-05$ & $2.18 \mathrm{E}-04$ & $1.79 \mathrm{E}-04$ & $9.51 \mathrm{E}-05$ \\
\hline \multirow[t]{2}{*}{ GWO } & 1 & $6.18 \mathrm{E}-05$ & $4.65 \mathrm{E}-09$ & $9.90 \mathrm{E}-05$ & $2.06 \mathrm{E}-04$ & $1.72 \mathrm{E}-04$ & $8.12 \mathrm{E}-05$ \\
\hline & 2 & $6.21 \mathrm{E}-05$ & $1.86 \mathrm{E}-06$ & $7.36 \mathrm{E}-05$ & $2.40 \mathrm{E}-04$ & $1.83 \mathrm{E}-04$ & $1.00 \mathrm{E}-04$ \\
\hline \multirow[t]{2}{*}{ NNA } & 1 & $3.24 \mathrm{E}-14$ & $1.67 \mathrm{E}-20$ & $1.36 \mathrm{E}-13$ & $1.71 \mathrm{E}-04$ & $1.71 \mathrm{E}-04$ & $3.01 \mathrm{E}-13$ \\
\hline & 2 & $8.82 \mathrm{E}-13$ & $1.13 \mathrm{E}-19$ & $1.44 \mathrm{E}-12$ & $1.79 \mathrm{E}-04$ & $1.79 \mathrm{E}-04$ & $6.99 \mathrm{E}-13$ \\
\hline \multirow[t]{2}{*}{$\mathrm{CBO}$} & 1 & $2.59 \mathrm{E}-21$ & $7.87 \mathrm{E}-23$ & $2.49 \mathrm{E}-21$ & $1.71 \mathrm{E}-04$ & $1.71 \mathrm{E}-04$ & $1.11 \mathrm{E}-16$ \\
\hline & 2 & $8.90 \mathrm{E}-18$ & $1.31 \mathrm{E}-18$ & $6.09 \mathrm{E}-18$ & $1.79 \mathrm{E}-04$ & $1.79 \mathrm{E}-04$ & $1.13 E-16$ \\
\hline \multirow[t]{2}{*}{ HHO } & 1 & $1.34 \mathrm{E}-04$ & $2.92 \mathrm{E}-06$ & $7.51 \mathrm{E}-05$ & $2.98 \mathrm{E}-04$ & $1.72 \mathrm{E}-04$ & $1.02 \mathrm{E}-04$ \\
\hline & 2 & 0.0072 & $1.81 \mathrm{E}-04$ & 0.0072 & 0.0039 & $3.03 \mathrm{E}-04$ & 0.0035 \\
\hline
\end{tabular}




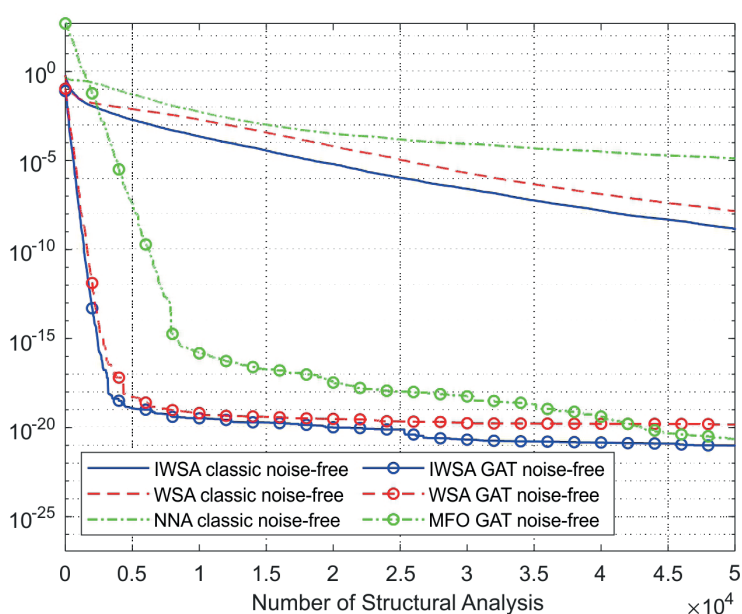

(a)

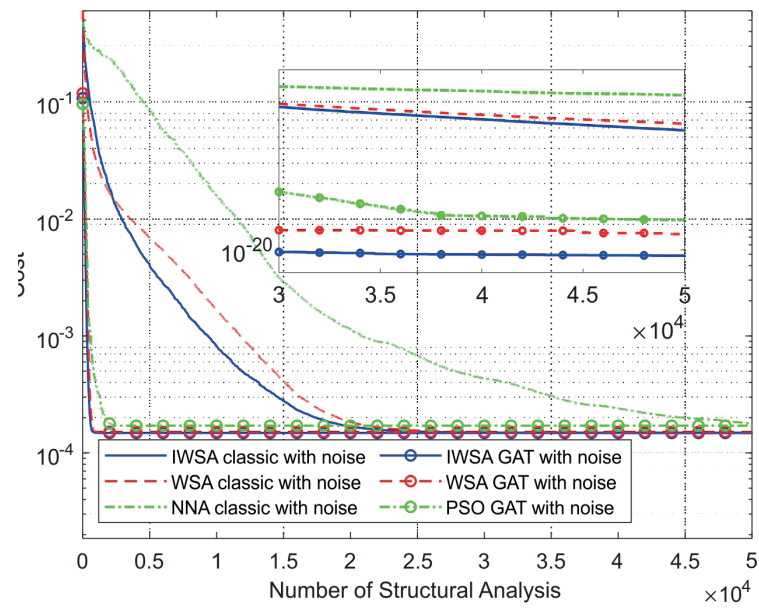

(b)

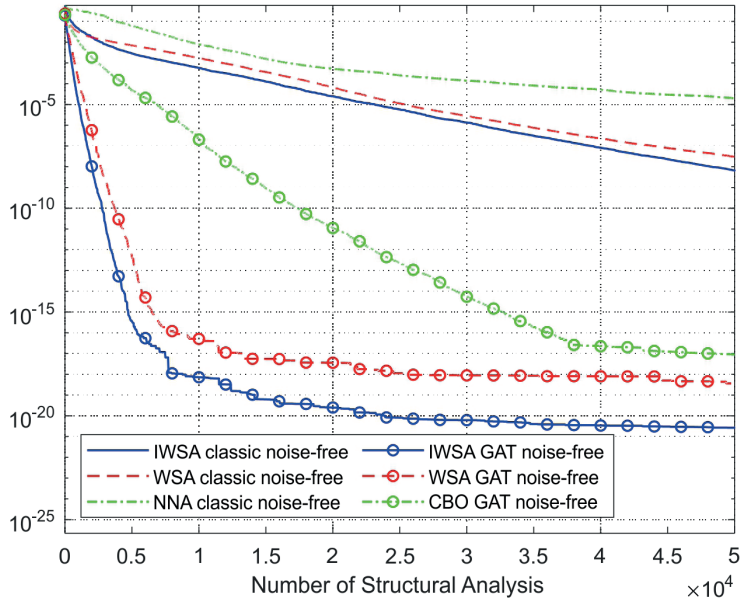

(c)

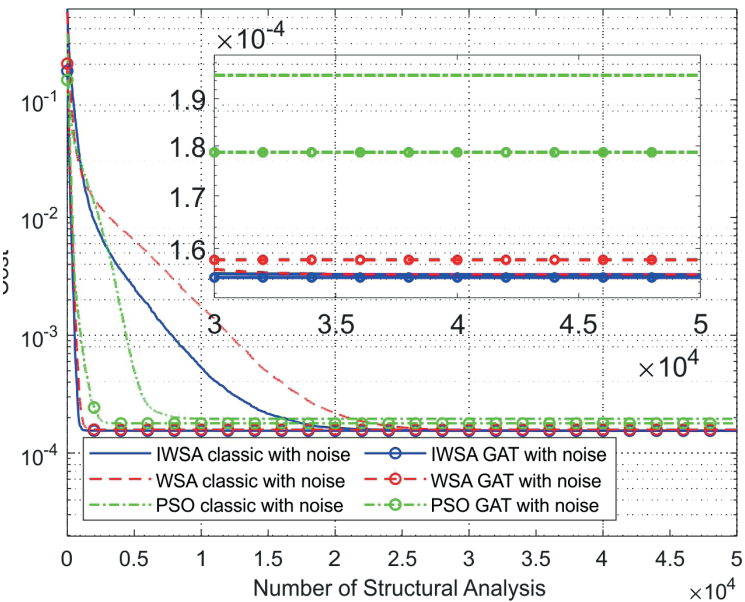

(d)

Fig. 8 Convergence curves of different methods for two-span bridge. (a) Noise-free state of scenario \#1; (b) with-noise state of scenario \#1; (c) Noisefree state of scenario \#2; (d) with-noise state of scenario \#2

- Damage $=$ IWSA Classic (Noise free) $\%$ IWSA GAT (Noise free) $\square$ IWSA Classic (1\% Noise) $\square$ IWSA GAT (1\% Noise)

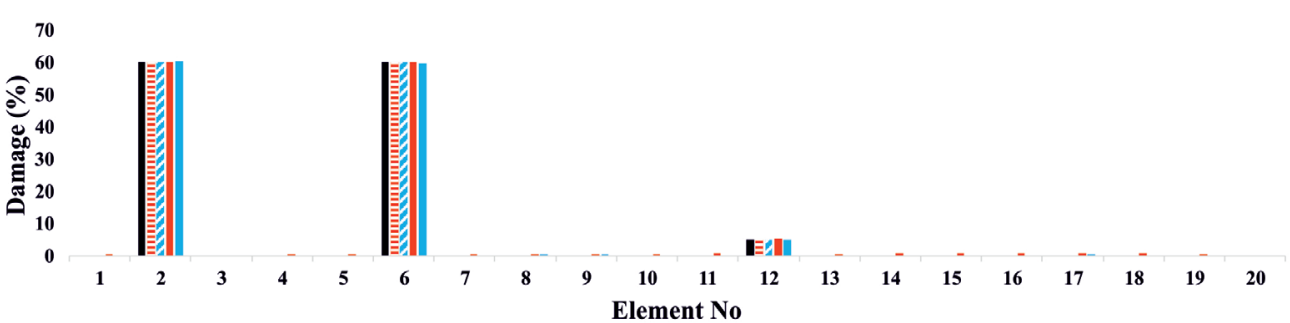

(a)

Damage = IWSA Classic (Noise free) 2 IWSA GAT (Noise free) $\quad$ IWSA Classic (1\% Noise) $\square$ IWSA GAT (1\% Noise)

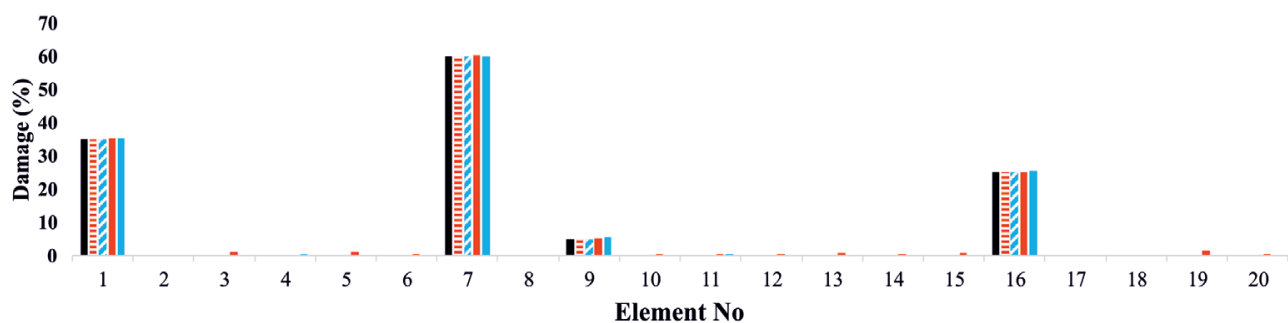

(b)

Fig. 9 The best detections obtained by the IWSA algorithm for Fixed-beam bridge (a) Scenario \#1; (b) Scenario \#2 


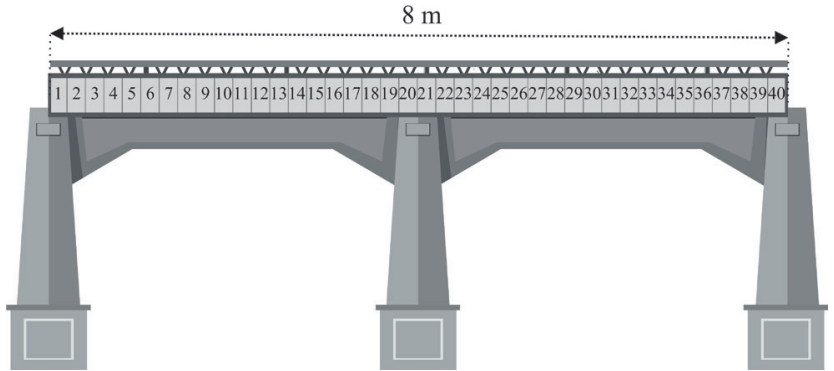

Fig. 10 Two-span continuous steel bridge

The comparison among the optimization algorithms via the classic inverse method is examined in Table 6 . In all tables, the best results are written in bold font. As seen, IWSA has the overall best performance among all algorithms. In the noise-free state, WSA and NNA are placed in the second and third ranks for both scenarios. Furthermore, in the with-noise condition, IWSA, WSA, and NNA obtained the minimum costs.

Comparing the algorithms' results for noise-free and with-noise cases, like the previous example, indicates that the noise-polluted data ruined solutions' quality.

The results of the examined optimization algorithms using GAT for this example are provided in Table 7. According to Table 7, except for the standard deviation of with-
Table 5 Damage scenarios for the two-span continuous steel bridge

\begin{tabular}{ccc}
\hline & Damaged elements & Damage severity \\
\hline Scenario \#1 & $1,9,23$, and 35 & $35 \% ., 50 \%, 5 \%$ and $50 \%$ \\
Scenario \#2 & $2,6,8,26$, and 32 & $45 \% ., 55 \%, 5 \%, 55 \%$ and $50 \%$ \\
\hline
\end{tabular}

noise cases, the IWSA generally obtained the optimum results in other statistical measures. ICA reached the minimum value in the noise-free condition, and WSA and CBO achieved acceptably good results in the examined terms.

Fig. 11 demonstrates the average convergence curves of IWSA, WSA, and the best algorithm among other optimizers reported in Tables 6 and 7. As shown, GAT accelerates the convergence process in all cases. For instance, in the with-noise cases, the proposed IWSA and WSA via GAT technique converged to optimum solutions in relatively low NSA.

The damage detection results of the IWSA using classic inverse and two-stage GAT methods, as well as the actual damages, are depicted in Fig. 12. This algorithm exhibits an entirely satisfactory accuracy for all cases; however, the GAT method has low errors in with-noise cases that show its robustness against noise contamination. But the classic method falsely identified many numbers of elements as damaged.

Table 6 A classic inverse method for the two-span continuous steel bridge

\begin{tabular}{|c|c|c|c|c|c|c|c|}
\hline \multirow[t]{2}{*}{ Algorithm } & \multirow[t]{2}{*}{ Scenario } & \multirow{2}{*}{$\begin{array}{c}\text { Noise-free } \\
\text { Average }\end{array}$} & \multicolumn{3}{|c|}{ With-Noise } & \multirow[b]{2}{*}{ Min } & \multirow[b]{2}{*}{ STD } \\
\hline & & & Min & STD & Average & & \\
\hline \multirow[t]{2}{*}{ IWSA } & 1 & $1.20 \mathrm{E}-15$ & 2.50E-17 & $1.12 \mathrm{E}-15$ & $1.68 \mathrm{E}-04$ & $1.67 E-04$ & $9.45 E-07$ \\
\hline & 2 & 8.55E-16 & 4.79E-17 & $1.00 \mathrm{E}-15$ & $1.28 \mathrm{E}-04$ & $1.28 \mathrm{E}-04$ & $2.18 E-07$ \\
\hline \multirow[t]{2}{*}{ WSA } & 1 & $2.95 \mathrm{E}-12$ & $2.37 \mathrm{E}-15$ & $1.17 \mathrm{E}-11$ & $1.67 E-04$ & $1.67 E-04$ & $1.40 \mathrm{E}-06$ \\
\hline & 2 & $1.07 \mathrm{E}-12$ & $2.66 \mathrm{E}-15$ & $1.50 \mathrm{E}-12$ & $1.29 \mathrm{E}-04$ & $1.28 E-04$ & $3.48 \mathrm{E}-07$ \\
\hline \multirow[t]{2}{*}{ PSO } & 1 & $6.74 \mathrm{E}-05$ & $4.42 \mathrm{E}-06$ & $8.25 \mathrm{E}-05$ & $3.43 \mathrm{E}-04$ & $1.73 \mathrm{E}-04$ & $2.65 \mathrm{E}-04$ \\
\hline & 2 & $3.89 \mathrm{E}-05$ & $3.23 \mathrm{E}-06$ & $4.68 \mathrm{E}-05$ & $1.61 \mathrm{E}-04$ & $1.33 \mathrm{E}-04$ & $2.70 \mathrm{E}-05$ \\
\hline \multirow[t]{2}{*}{ GA } & 1 & 0.0092 & 0.0045 & 0.0037 & 0.0088 & 0.0044 & 0.0041 \\
\hline & 2 & 0.0059 & 0.0026 & 0.0029 & 0.0066 & 0.0022 & 0.0025 \\
\hline \multirow[t]{2}{*}{ ICA } & 1 & 0.0019 & $3.21 \mathrm{E}-04$ & 0.0018 & 0.0014 & $2.34 \mathrm{E}-04$ & $8.54 \mathrm{E}-04$ \\
\hline & 2 & $2.54 \mathrm{E}-04$ & $7.37 \mathrm{E}-05$ & $1.50 \mathrm{E}-04$ & $4.55 \mathrm{E}-04$ & $1.62 \mathrm{E}-04$ & $2.39 \mathrm{E}-04$ \\
\hline \multirow[t]{2}{*}{ MFO } & 1 & 0.0141 & $5.44 \mathrm{E}-16$ & 0.0515 & 0.0271 & $1.73 \mathrm{E}-04$ & 0.0738 \\
\hline & 2 & 0.0031 & $8.78 \mathrm{E}-16$ & 0.0061 & $7.80 \mathrm{E}-04$ & $1.36 \mathrm{E}-04$ & 0.0015 \\
\hline \multirow[t]{2}{*}{ GWO } & 1 & $4.25 \mathrm{E}-04$ & $2.54 \mathrm{E}-05$ & 0.0011 & 0.0023 & $2.10 \mathrm{E}-04$ & 0.0044 \\
\hline & 2 & $3.60 \mathrm{E}-04$ & $4.01 \mathrm{E}-05$ & $6.06 \mathrm{E}-04$ & 0.002 & $1.85 \mathrm{E}-04$ & 0.0049 \\
\hline \multirow[t]{2}{*}{ NNA } & 1 & $3.74 \mathrm{E}-06$ & $2.31 \mathrm{E}-07$ & $2.87 \mathrm{E}-06$ & $1.70 \mathrm{E}-04$ & $1.67 E-04$ & $2.45 \mathrm{E}-06$ \\
\hline & 2 & $1.56 \mathrm{E}-06$ & $6.87 \mathrm{E}-08$ & $1.31 \mathrm{E}-06$ & $1.30 \mathrm{E}-04$ & $1.28 E-04$ & $1.12 \mathrm{E}-06$ \\
\hline \multirow[t]{2}{*}{$\mathrm{CBO}$} & 1 & $1.23 \mathrm{E}-05$ & $1.39 \mathrm{E}-07$ & $1.35 \mathrm{E}-05$ & $1.81 \mathrm{E}-04$ & $1.68 \mathrm{E}-04$ & $1.71 \mathrm{E}-05$ \\
\hline & 2 & $3.39 \mathrm{E}-06$ & $4.78 \mathrm{E}-07$ & $2.08 \mathrm{E}-06$ & $1.30 \mathrm{E}-04$ & $1.28 E-04$ & $1.73 \mathrm{E}-06$ \\
\hline \multirow[t]{2}{*}{ HHO } & 1 & 0.0199 & 0.008 & 0.0085 & 0.0223 & 0.0099 & 0.0097 \\
\hline & 2 & 0.0221 & 0.0024 & 0.0102 & 0.0218 & 0.0027 & 0.0098 \\
\hline
\end{tabular}


Table 7 Graph-based Adaptive Threshold for Modal Strain Energy in the two-stage method for the two-span continuous steel bridge

\begin{tabular}{|c|c|c|c|c|c|c|c|}
\hline \multirow[t]{2}{*}{ Algorithm } & \multirow[t]{2}{*}{ Scenario } & \multirow{2}{*}{$\begin{array}{c}\text { Noise-free } \\
\text { Average }\end{array}$} & \multicolumn{3}{|c|}{ With-Noise } & \multirow[b]{2}{*}{ Min } & \multirow[b]{2}{*}{ STD } \\
\hline & & & Min & STD & Average & & \\
\hline \multirow[t]{2}{*}{ IWSA } & 1 & 8.00E-16 & 1.12E-19 & $2.41 \mathrm{E}-15$ & $1.47 E-04$ & $1.47 E-04$ & $1.41 \mathrm{E}-11$ \\
\hline & 2 & $4.58 E-20$ & $2.90 \mathrm{E}-21$ & $5.49 \mathrm{E}-20$ & $1.26 \mathrm{E}-04$ & $1.26 \mathrm{E}-04$ & $5.74 \mathrm{E}-09$ \\
\hline \multirow[t]{2}{*}{ WSA } & 1 & $1.33 \mathrm{E}-14$ & $1.44 \mathrm{E}-15$ & $1.80 \mathrm{E}-14$ & $1.55 \mathrm{E}-04$ & $1.55 \mathrm{E}-04$ & $9.82 \mathrm{E}-08$ \\
\hline & 2 & $1.37 \mathrm{E}-18$ & $8.26 \mathrm{E}-21$ & $4.22 \mathrm{E}-18$ & $1.33 \mathrm{E}-04$ & $1.33 \mathrm{E}-04$ & $1.84 \mathrm{E}-15$ \\
\hline \multirow[t]{2}{*}{ PSO } & 1 & $1.35 \mathrm{E}-07$ & $1.66 \mathrm{E}-10$ & $3.23 \mathrm{E}-07$ & $1.55 \mathrm{E}-04$ & $1.55 \mathrm{E}-04$ & $3.70 \mathrm{E}-07$ \\
\hline & 2 & $2.10 \mathrm{E}-17$ & $9.44 \mathrm{E}-21$ & $7.18 \mathrm{E}-17$ & $1.60 \mathrm{E}-04$ & $1.60 \mathrm{E}-04$ & $1.86 \mathrm{E}-14$ \\
\hline \multirow[t]{2}{*}{ GA } & 1 & 0.0102 & $9.05 \mathrm{E}-04$ & 0.0125 & 0.0069 & 4.65E-04 & 0.006 \\
\hline & 2 & $2.15 \mathrm{E}-05$ & $2.10 \mathrm{E}-06$ & $1.14 \mathrm{E}-05$ & $1.98 \mathrm{E}-04$ & $1.66 \mathrm{E}-04$ & $2.42 \mathrm{E}-05$ \\
\hline \multirow[t]{2}{*}{ ICA } & 1 & $3.79 \mathrm{E}-05$ & $1.37 \mathrm{E}-11$ & 8.97E-05 & $1.72 \mathrm{E}-04$ & $1.53 \mathrm{E}-04$ & $2.89 \mathrm{E}-05$ \\
\hline & 2 & $1.81 \mathrm{E}-16$ & $2.90 \mathrm{E}-21$ & $4.15 \mathrm{E}-16$ & $1.59 \mathrm{E}-04$ & $1.59 \mathrm{E}-04$ & $4.01 \mathrm{E}-07$ \\
\hline \multirow[t]{2}{*}{ MFO } & 1 & 0.0151 & $2.83 \mathrm{E}-18$ & 0.049 & 0.0223 & $1.57 \mathrm{E}-04$ & 0.068 \\
\hline & 2 & $4.55 \mathrm{E}-06$ & $9.72 \mathrm{E}-21$ & $1.11 \mathrm{E}-05$ & 0.0014 & $1.60 \mathrm{E}-04$ & 0.0046 \\
\hline \multirow[t]{2}{*}{ GWO } & 1 & $3.64 \mathrm{E}-04$ & $1.51 \mathrm{E}-05$ & 0.0015 & $7.56 \mathrm{E}-04$ & $1.80 \mathrm{E}-04$ & 0.0025 \\
\hline & 2 & 4.07E-05 & $7.08 \mathrm{E}-07$ & $2.81 \mathrm{E}-05$ & $2.95 \mathrm{E}-04$ & $1.66 \mathrm{E}-04$ & $4.68 \mathrm{E}-04$ \\
\hline \multirow[t]{2}{*}{ NNA } & 1 & 4.35E-08 & $9.41 \mathrm{E}-12$ & $4.98 \mathrm{E}-08$ & $1.55 \mathrm{E}-04$ & $1.55 \mathrm{E}-04$ & $2.83 \mathrm{E}-07$ \\
\hline & 2 & $1.10 \mathrm{E}-13$ & $3.68 \mathrm{E}-18$ & $2.62 \mathrm{E}-13$ & $1.60 \mathrm{E}-04$ & $1.60 \mathrm{E}-04$ & $1.19 \mathrm{E}-08$ \\
\hline \multirow[t]{2}{*}{$\mathrm{CBO}$} & 1 & $6.77 \mathrm{E}-09$ & $5.06 \mathrm{E}-10$ & $5.39 \mathrm{E}-09$ & $1.55 \mathrm{E}-04$ & $1.55 \mathrm{E}-04$ & $4.87 E-12$ \\
\hline & 2 & $2.41 \mathrm{E}-19$ & $1.64 \mathrm{E}-21$ & $4.62 \mathrm{E}-19$ & $1.60 \mathrm{E}-04$ & $1.60 \mathrm{E}-04$ & $1.83 E-16$ \\
\hline \multirow[t]{2}{*}{$\mathrm{HHO}$} & 1 & 0.0158 & $1.79 \mathrm{E}-04$ & 0.0089 & 0.0166 & 0.0049 & 0.0095 \\
\hline & 2 & 0.0022 & $5.40 \mathrm{E}-05$ & 0.0022 & 0.0061 & 0.0024 & 0.0034 \\
\hline
\end{tabular}

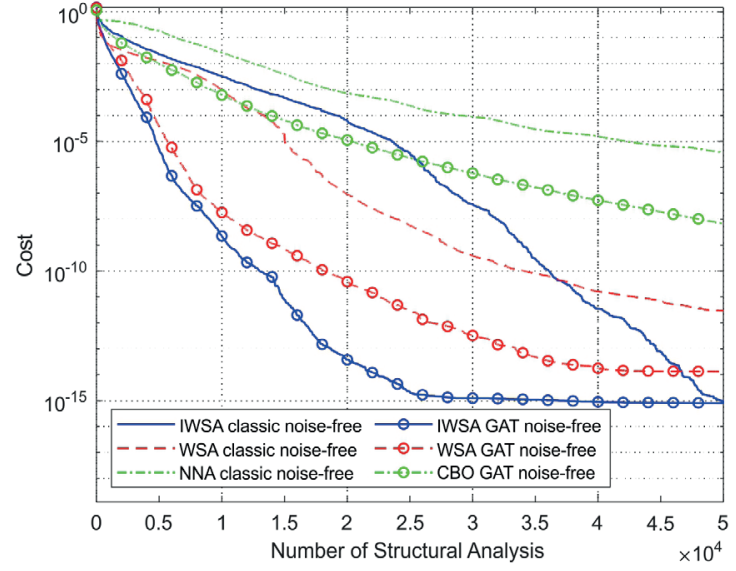

(a)

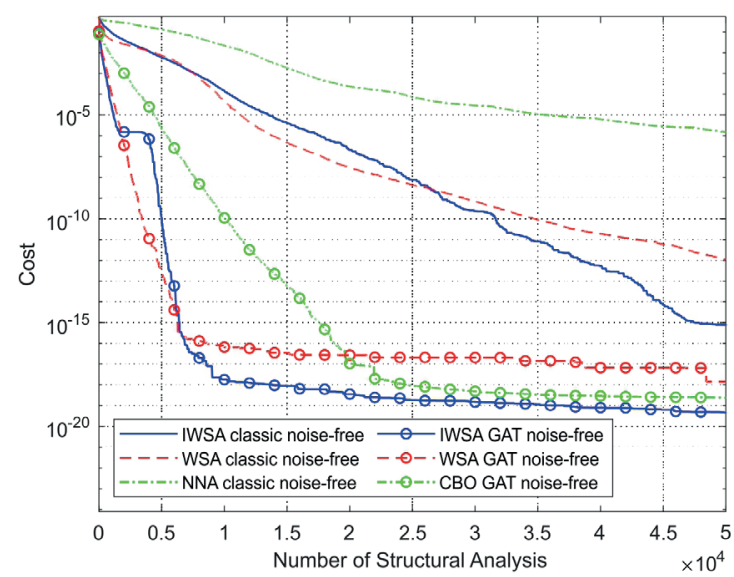

(c)

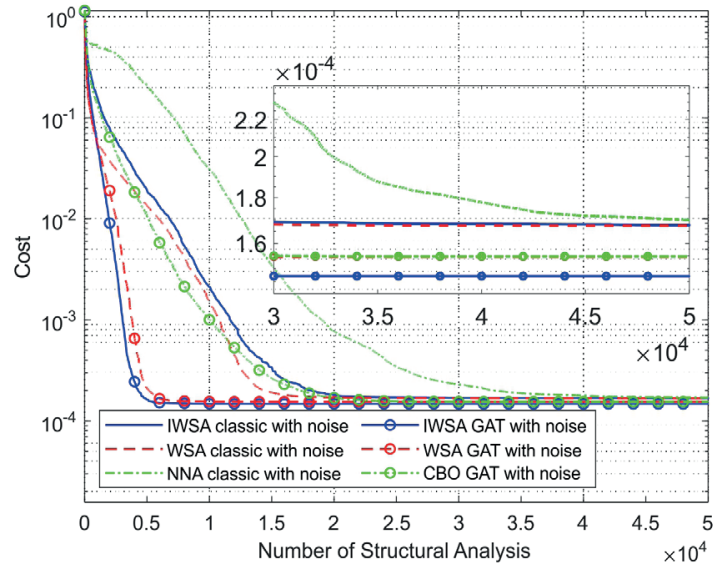

(b)

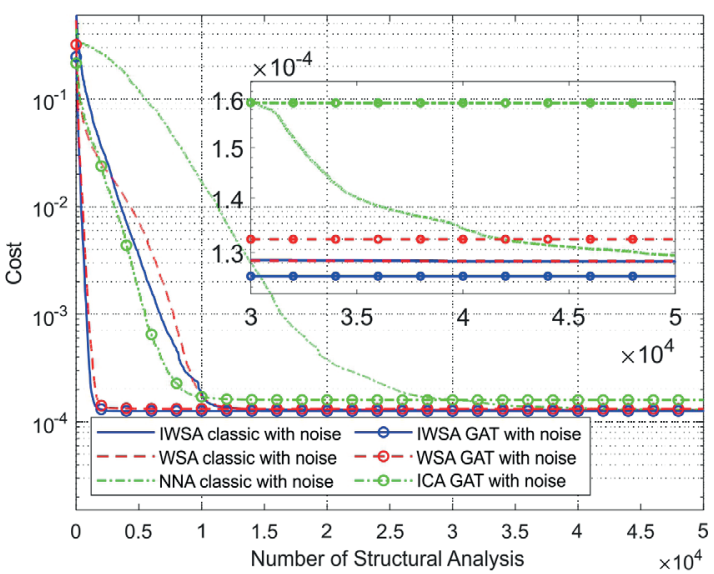

(d)

Fig. 11 Convergence curves of different methods for two-span bridge (a) Noise-free state of scenario \#1; (b) with-noise state of scenario \#1 (c) Noisefree state of scenario \#2; (d) with-noise state of scenario \#2 


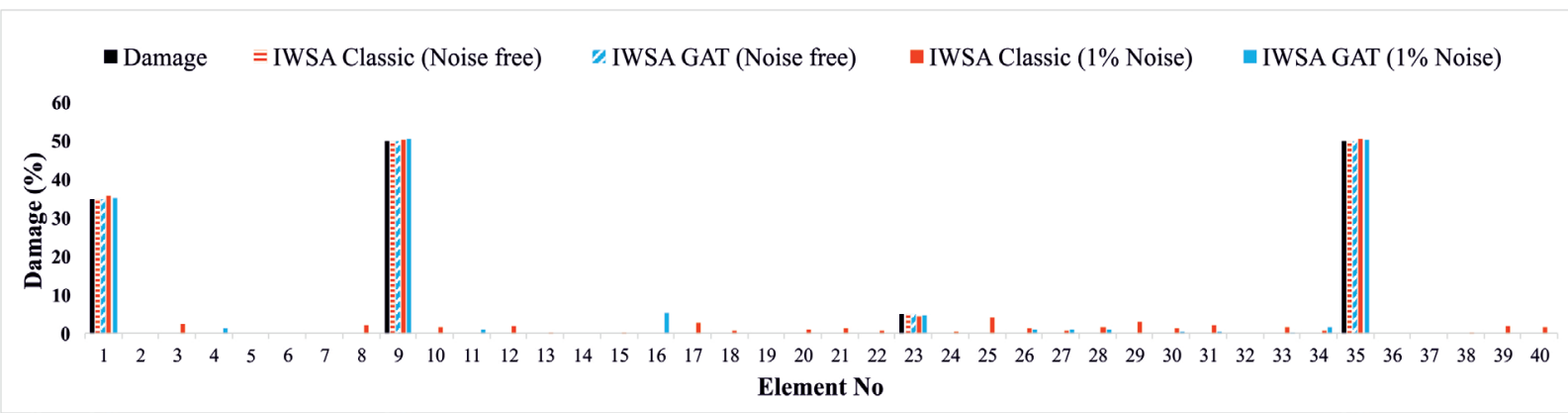

(a)

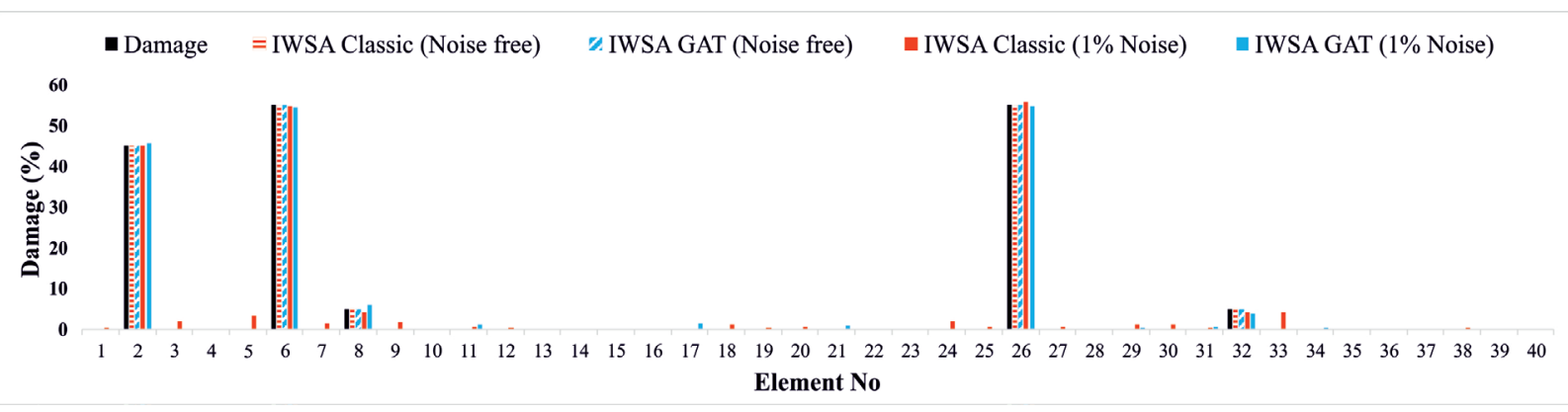

(b)

Fig. 12 The best detections obtained by the IWSA algorithm for the two-span continuous steel bridge (a) Scenario \#1; (b) Scenario \#2

\subsection{A concrete portal frame structure}

As shown in Fig. 13, in the last numerical example, the algorithms are applied to identify the damages of a concrete portal frame structure divided into 56 elements. The height and width of this frame's rectangular cross-section are $0.24 \mathrm{~m}$ and $0.14 \mathrm{~m}$, respectively. The modulus of elasticity and mass density are $25 \mathrm{GPa}$ and $2500 \mathrm{~kg} / \mathrm{m}^{3}$, respectively. The frame is modeled using two-dimensional frame elements with three degrees of freedom at each node. Two damage scenarios are considered according to Table 8, and like the previous examples, with-noise and noise-free cases are examined [16].

In the first scenario, the $\overline{M S E B I}$ value of elements 7 and 22 are the only positive values; while, the GAT method suggests elements $1,7,22$, and 50 as damaged ones, which covers all faulty elements. Moreover, in the second scenario, the $\overline{M S E B I}$ of elements 18, 24, and 51 have positive values. The previous two-stage method cannot detect element 33; while the proposed GAT method suggests elements 18, 24, 33, and 51 as damaged elements that are the damaged elements in this scenario.

The comparison among the examined optimization algorithms in the classic inverse method in terms of statistical measures are provided in Table 9. As seen, the IWSA outperforms all algorithms for noise-free and with-noise states, and it is evident that noise has a detrimental effect on cost values. Besides, WSA in the noise-free state of the first scenario and WSA, CBO, and NNA in the second scenario's with-noise case has reasonably lower cost values.

The performances of the examined optimization algorithms using the GAT method are compared in Table 10. As seen, IWSA reached the best average value among algorithms. By considering the noise-free state, the PSO and $\mathrm{CBO}$ in the first damage scenario and WSA and CBO in the second scenario are placed in the next places. In the

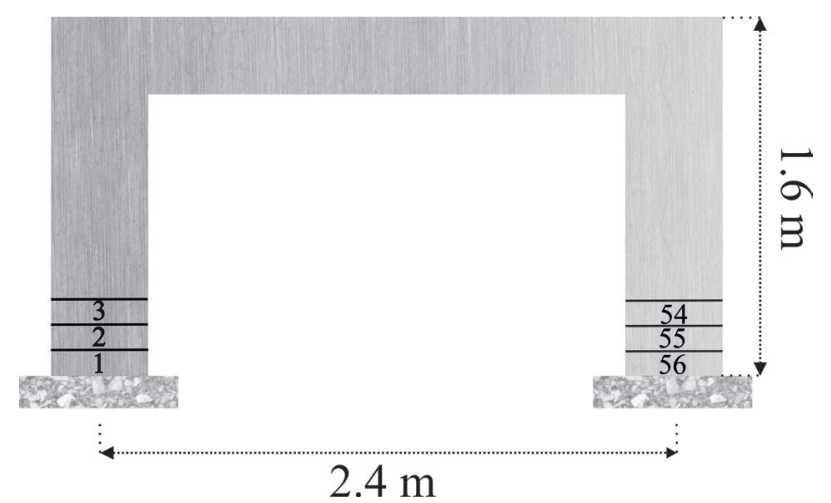

Fig. 13 A concrete portal frame structure

Table 8 Damage scenarios for the concrete portal frame structure

\begin{tabular}{lcc}
\hline & Damaged elements & Damage severity \\
\hline Scenario \#1 & 7,22, and 50 & $70 \%, 50 \%$ and $5 \%$ \\
Scenario \#2 & $18,24,33$, and 51 & $40 \%, 35 \%, 5 \%$ and $50 \%$ \\
\hline
\end{tabular}


Table 9 A classic inverse method for the concrete portal frame structure

\begin{tabular}{|c|c|c|c|c|c|c|c|}
\hline \multirow[t]{2}{*}{ Algorithm } & \multirow[t]{2}{*}{ Scenario } & \multicolumn{3}{|c|}{ Noise-free } & \multicolumn{3}{|c|}{ With-Noise } \\
\hline & & Average & Min & STD & Average & Min & STD \\
\hline \multirow[t]{2}{*}{ IWSA } & 1 & $1.17 E-15$ & $1.58 \mathrm{E}-16$ & 8.83E-16 & $1.70 \mathrm{E}-04$ & $1.70 \mathrm{E}-04$ & $3.88 E-09$ \\
\hline & 2 & $1.02 \mathrm{E}-15$ & 8.65E-17 & $8.48 E-16$ & $1.69 \mathrm{E}-04$ & $1.68 E-04$ & $6.45 \mathrm{E}-08$ \\
\hline \multirow[t]{2}{*}{ WSA } & 1 & $2.39 \mathrm{E}-07$ & $2.30 \mathrm{E}-16$ & $1.07 \mathrm{E}-06$ & $1.70 \mathrm{E}-04$ & $1.70 \mathrm{E}-04$ & $2.49 \mathrm{E}-07$ \\
\hline & 2 & $1.50 \mathrm{E}-07$ & $3.00 \mathrm{E}-15$ & $4.61 \mathrm{E}-07$ & $1.74 \mathrm{E}-04$ & $1.69 \mathrm{E}-04$ & $2.23 \mathrm{E}-05$ \\
\hline \multirow[t]{2}{*}{ PSO } & 1 & $3.07 \mathrm{E}-05$ & 1.12E-06 & $5.00 \mathrm{E}-05$ & $1.97 \mathrm{E}-04$ & $1.78 \mathrm{E}-04$ & $2.13 \mathrm{E}-05$ \\
\hline & 2 & $1.71 \mathrm{E}-05$ & 4.39E-06 & 1.19E-05 & $1.80 \mathrm{E}-04$ & $1.69 \mathrm{E}-04$ & $9.64 \mathrm{E}-06$ \\
\hline \multirow[t]{2}{*}{ GA } & 1 & $5.45 \mathrm{E}-04$ & $2.20 \mathrm{E}-04$ & $3.05 \mathrm{E}-04$ & $6.72 \mathrm{E}-04$ & $3.21 \mathrm{E}-04$ & $2.02 \mathrm{E}-04$ \\
\hline & 2 & $4.74 \mathrm{E}-04$ & $2.37 \mathrm{E}-04$ & $1.87 \mathrm{E}-04$ & $6.84 \mathrm{E}-04$ & $3.08 \mathrm{E}-04$ & $3.61 \mathrm{E}-04$ \\
\hline \multirow[t]{2}{*}{ ICA } & 1 & $1.66 \mathrm{E}-04$ & $1.12 \mathrm{E}-05$ & 4.09E-04 & 4.34E-04 & $1.78 \mathrm{E}-04$ & $6.34 \mathrm{E}-04$ \\
\hline & 2 & $1.28 \mathrm{E}-04$ & $2.68 \mathrm{E}-06$ & $2.13 \mathrm{E}-04$ & $2.76 \mathrm{E}-04$ & $1.80 \mathrm{E}-04$ & $2.29 \mathrm{E}-04$ \\
\hline \multirow[t]{2}{*}{ MFO } & 1 & $5.61 \mathrm{E}-04$ & $1.16 \mathrm{E}-15$ & 7.16E-04 & $4.42 \mathrm{E}-04$ & $1.70 \mathrm{E}-04$ & $4.43 \mathrm{E}-04$ \\
\hline & 2 & $1.55 \mathrm{E}-04$ & $1.98 \mathrm{E}-15$ & $1.74 \mathrm{E}-04$ & 4.30E-04 & $1.67 \mathrm{E}-04$ & $6.18 \mathrm{E}-04$ \\
\hline \multirow[t]{2}{*}{ GWO } & 1 & $2.32 \mathrm{E}-04$ & 7.33E-06 & $4.20 \mathrm{E}-04$ & 4.10E-04 & $1.80 \mathrm{E}-04$ & 4.18E-04 \\
\hline & 2 & $1.03 \mathrm{E}-04$ & $6.02 \mathrm{E}-06$ & $1.18 \mathrm{E}-04$ & $2.84 \mathrm{E}-04$ & $1.75 \mathrm{E}-04$ & $3.63 \mathrm{E}-04$ \\
\hline \multirow[t]{2}{*}{ NNA } & 1 & $2.61 \mathrm{E}-07$ & $1.98 \mathrm{E}-08$ & $7.95 \mathrm{E}-07$ & $1.71 \mathrm{E}-04$ & $1.70 \mathrm{E}-04$ & $1.47 \mathrm{E}-06$ \\
\hline & 2 & $2.55 \mathrm{E}-07$ & $1.43 \mathrm{E}-08$ & $3.39 \mathrm{E}-07$ & $1.69 E-04$ & $1.68 E-04$ & 4.91E-07 \\
\hline \multirow[t]{2}{*}{$\mathrm{CBO}$} & 1 & $1.48 \mathrm{E}-07$ & $4.10 \mathrm{E}-09$ & $1.94 \mathrm{E}-07$ & $1.93 \mathrm{E}-04$ & $1.70 \mathrm{E}-04$ & $1.01 \mathrm{E}-04$ \\
\hline & 2 & $2.93 \mathrm{E}-07$ & $1.15 \mathrm{E}-08$ & $5.15 \mathrm{E}-07$ & $1.69 \mathrm{E}-04$ & $1.68 \mathrm{E}-04$ & $1.06 \mathrm{E}-06$ \\
\hline \multirow[t]{2}{*}{$\mathrm{HHO}$} & 1 & 0.0054 & 0.0015 & 0.0017 & 0.0047 & $6.71 \mathrm{E}-04$ & 0.0019 \\
\hline & 2 & 0.0035 & 0.0014 & 0.0016 & 0.0035 & $9.97 \mathrm{E}-04$ & 0.0014 \\
\hline
\end{tabular}

Table 10 Graph-based Adaptive Threshold for Modal Strain Energy in the two-stage method for the concrete portal frame structure

\begin{tabular}{|c|c|c|c|c|c|c|c|}
\hline \multirow[t]{2}{*}{ Algorithm } & \multirow[t]{2}{*}{ Scenario } & \multicolumn{3}{|c|}{ Noise-free } & \multicolumn{3}{|c|}{ With-Noise } \\
\hline & & Average & Min & STD & Average & Min & STD \\
\hline \multirow[t]{2}{*}{ IWSA } & 1 & $2.22 \mathrm{E}-21$ & $1.14 \mathrm{E}-22$ & 3.01E-21 & $1.60 \mathrm{E}-04$ & $1.60 \mathrm{E}-04$ & $1.78 \mathrm{E}-08$ \\
\hline & 2 & $3.23 E-21$ & 8.03E-22 & $1.99 \mathrm{E}-21$ & 1.69E-04 & $1.69 E-04$ & $4.50 \mathrm{E}-09$ \\
\hline \multirow[t]{2}{*}{ WSA } & 1 & 2.22E-21 & $2.19 \mathrm{E}-22$ & $3.01 E-21$ & $1.64 \mathrm{E}-04$ & $1.64 \mathrm{E}-04$ & $1.21 \mathrm{E}-07$ \\
\hline & 2 & $4.12 \mathrm{E}-21$ & $3.34 \mathrm{E}-22$ & $3.20 \mathrm{E}-21$ & $1.87 \mathrm{E}-04$ & $1.87 \mathrm{E}-04$ & $1.56 \mathrm{E}-07$ \\
\hline \multirow[t]{2}{*}{ PSO } & 1 & $6.23 \mathrm{E}-21$ & $1.71 E-23$ & $1.26 \mathrm{E}-20$ & $1.64 \mathrm{E}-04$ & $1.64 \mathrm{E}-04$ & $3.29 \mathrm{E}-07$ \\
\hline & 2 & $1.28 \mathrm{E}-20$ & 2.52E-23 & $1.84 \mathrm{E}-20$ & $1.96 \mathrm{E}-04$ & $1.96 \mathrm{E}-04$ & 4.43E-07 \\
\hline \multirow[t]{2}{*}{ GA } & 1 & $1.11 \mathrm{E}-05$ & $6.02 \mathrm{E}-07$ & $1.17 \mathrm{E}-05$ & 4.37E-04 & $2.68 \mathrm{E}-04$ & $1.57 \mathrm{E}-04$ \\
\hline & 2 & $1.52 \mathrm{E}-06$ & $3.58 \mathrm{E}-20$ & $1.78 \mathrm{E}-06$ & $6.29 \mathrm{E}-04$ & $3.27 \mathrm{E}-04$ & $2.18 \mathrm{E}-04$ \\
\hline \multirow[t]{2}{*}{ ICA } & 1 & $4.69 \mathrm{E}-19$ & $5.55 \mathrm{E}-23$ & $1.53 \mathrm{E}-18$ & $1.68 \mathrm{E}-04$ & 1.64E-04 & $3.73 \mathrm{E}-06$ \\
\hline & 2 & $1.53 \mathrm{E}-16$ & $5.44 \mathrm{E}-21$ & $4.09 \mathrm{E}-16$ & $2.04 \mathrm{E}-04$ & $1.92 \mathrm{E}-04$ & $1.19 \mathrm{E}-05$ \\
\hline \multirow[t]{2}{*}{ MFO } & 1 & $1.26 \mathrm{E}-20$ & $7.17 \mathrm{E}-22$ & $2.03 \mathrm{E}-20$ & 4.72E-04 & $1.64 \mathrm{E}-04$ & $9.42 \mathrm{E}-04$ \\
\hline & 2 & $5.84 \mathrm{E}-07$ & $3.74 \mathrm{E}-22$ & $2.61 \mathrm{E}-06$ & 4.89E-04 & $1.97 \mathrm{E}-04$ & $5.19 \mathrm{E}-04$ \\
\hline \multirow[t]{2}{*}{ GWO } & 1 & $3.06 \mathrm{E}-07$ & $9.30 \mathrm{E}-10$ & $3.95 \mathrm{E}-07$ & $1.72 \mathrm{E}-04$ & $1.68 \mathrm{E}-04$ & $3.78 \mathrm{E}-06$ \\
\hline & 2 & $1.91 \mathrm{E}-06$ & $2.66 \mathrm{E}-10$ & 4.17E-06 & $2.48 \mathrm{E}-04$ & $2.04 \mathrm{E}-04$ & $1.32 \mathrm{E}-04$ \\
\hline \multirow[t]{2}{*}{ NNA } & 1 & $1.17 \mathrm{E}-14$ & $1.16 \mathrm{E}-20$ & $3.52 \mathrm{E}-14$ & $1.64 \mathrm{E}-04$ & $1.64 \mathrm{E}-04$ & $1.02 \mathrm{E}-06$ \\
\hline & 2 & $8.11 \mathrm{E}-17$ & $2.24 \mathrm{E}-20$ & $2.06 \mathrm{E}-16$ & $1.96 \mathrm{E}-04$ & $1.96 \mathrm{E}-04$ & $1.83 \mathrm{E}-07$ \\
\hline \multirow[t]{2}{*}{$\mathrm{CBO}$} & 1 & $1.23 \mathrm{E}-20$ & $2.44 \mathrm{E}-22$ & $2.43 \mathrm{E}-20$ & $1.64 \mathrm{E}-04$ & $1.64 \mathrm{E}-04$ & $7.73 E-10$ \\
\hline & 2 & $1.08 \mathrm{E}-20$ & $9.09 \mathrm{E}-22$ & $1.23 \mathrm{E}-20$ & $1.96 \mathrm{E}-04$ & $1.96 \mathrm{E}-04$ & $5.27 \mathrm{E}-11$ \\
\hline \multirow[t]{2}{*}{$\mathrm{HHO}$} & 1 & 1.19E-05 & 2.91E-09 & $9.31 \mathrm{E}-06$ & 0.0057 & 0.0027 & 0.0018 \\
\hline & 2 & $9.96 \mathrm{E}-06$ & $7.08 \mathrm{E}-09$ & $1.32 \mathrm{E}-05$ & 0.0036 & $9.85 \mathrm{E}-04$ & 0.001 \\
\hline
\end{tabular}


with-noise state, the results are relatively near each other; however, the IWSA presents the minimum cost and minimum average, and $\mathrm{CBO}$ provides the best standard deviation, among others.

Fig. 14 demonstrates the average convergence curves for IWSA, WSA, and the best algorithm among the other optimizers mentioned in Tables 9 and 10. It can be seen that the GAT sharply accelerated the optimization process compared to the classic inverse method. As demonstrated in Figs. 14(a) and 14(c), WSA initially has a high convergence rate, but after about $60 \%-80 \%$ of NSA, IWSA outperforms both algorithms. Although in most cases, the GAT resulted in a better cost than that of the classic method, the classic method finds slightly better results in Fig. 14(c). This is because of the presence of noise that disturbs the values of the objective function.

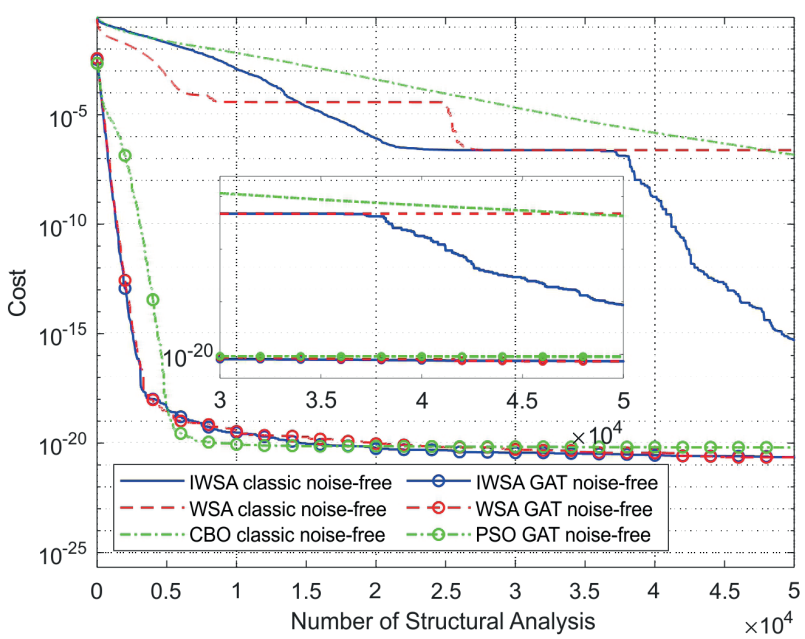

(a)

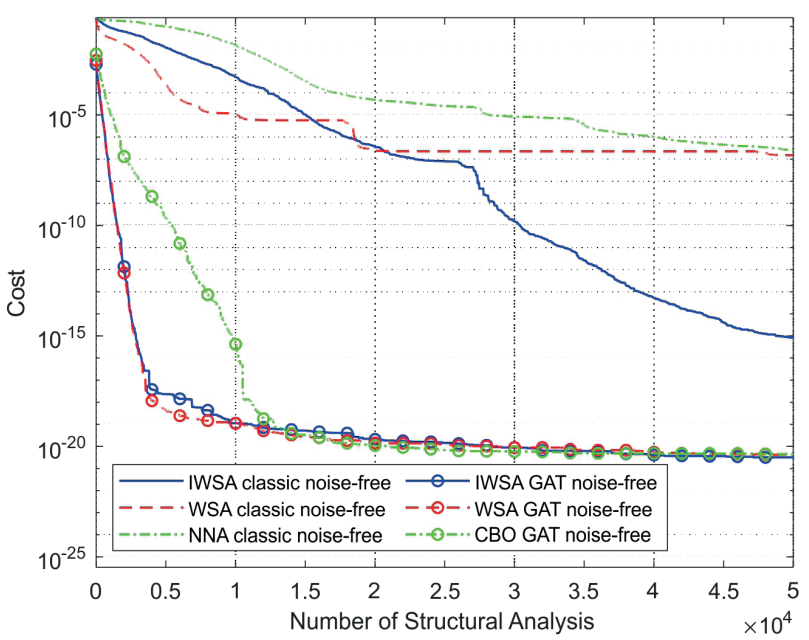

(c)
In Fig. 15, the optimum solutions obtained by IWSA are illustrated. As seen in the noise-free state, both methods successfully identified the location and severity of damages, but when data are polluted with noise, the classic inverse method falsely detects $17 \%$ damage in element 56 in both scenarios. However, the GAT is relatively robust against noise contamination.

\section{Conclusions}

This work presented the GAT algorithm as a new technique for structural damage localization that relies on modal strain energy and graph theory. In this technique, an adaptive threshold is introduced, which effectively nominates extra members as suspicious damaged elements that could not be detected by the traditional modal strain energy-based index (MSEBI). After identifying the

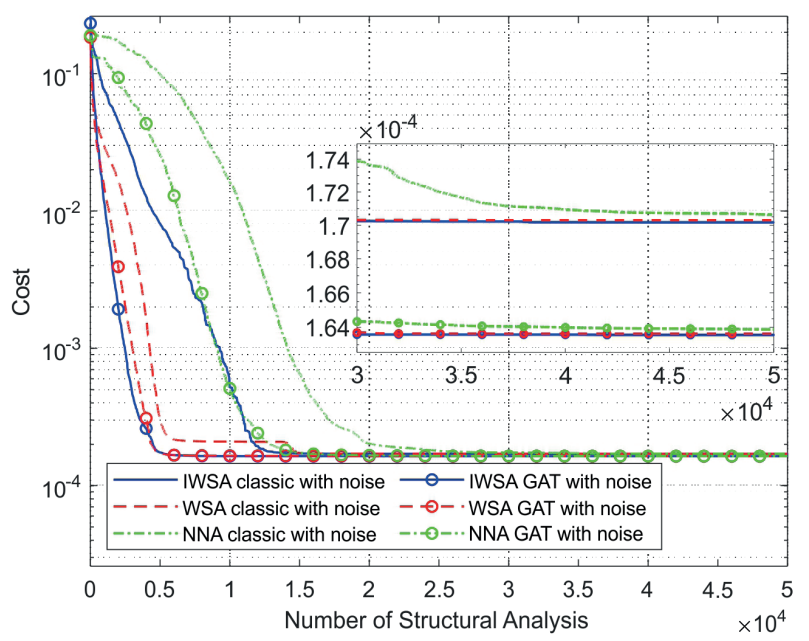

(b)

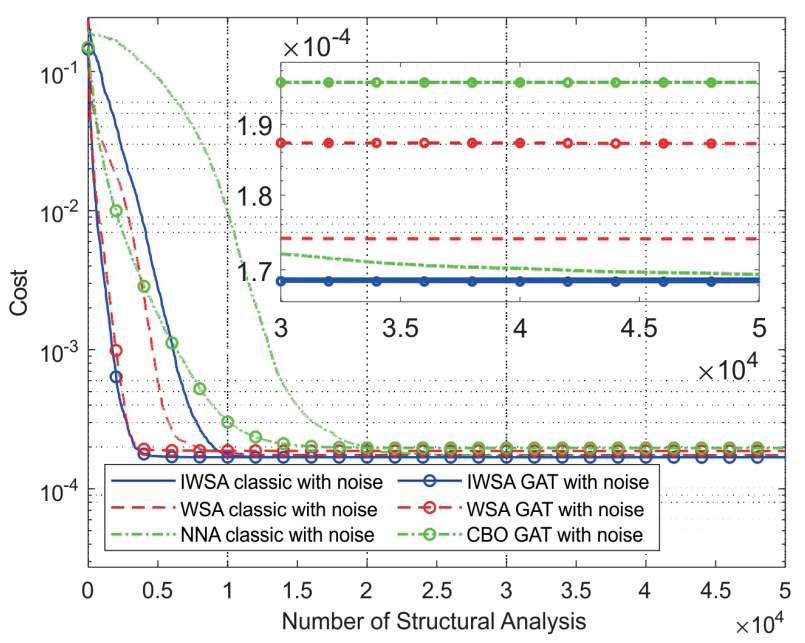

(d)

Fig. 14 Convergence curves of different methods for 56-element frame (a) Noise-free state of scenario \#1; (b) with-noise state of scenario \#1; 
candidate elements, their damage severity is determined by an optimization algorithm. To this goal, an improved version of a new nature-inspired multi-population algorithm known as WSA has been introduced, and along with the other nine algorithms, have been applied to damage detection of several structures. The results confirm that the proposed GAT can effectively perform damage localization so that all faulty elements are considered optimization variables. According to the results that were obtained by incomplete modal data and noise effects, it can be concluded that implementing GAT in the first stage speeds up the convergence rate, increase the accuracy of damage detection, and achieves more robustness against noise. In order to check the computational time for each step of the proposed method, we conducted a set of numerical experiments whose results are summarized in the following figures. As can be seen, in the first step, as the number of elements increases, it takes a longer time to calculate
MSEBI and GAT and thereby to detect candidate elements. However, the computational time for a 100 -element beam is still negligible (about 0.04 seconds). The average time for structural analysis (Fig. 16(b)) shows that larger structures, as expected, need longer times for a single modal analysis. In metaheuristic algorithms, the second step's accumulated time can be controlled through the maximum number of structural analyses (MaxNSA) parameters. The user can set this parameter considering the complexity of the problem.

Furthermore, IWSA exhibits efficient optimization performance concerning other popular algorithms. Therefore, these methods not only reduce the computational cost of inverse damage detection but also increases accuracy. As future works, to enhance damage detection methods, the authors intend to investigate other potentials of graph theory and metaheuristic optimization algorithms in this domain.

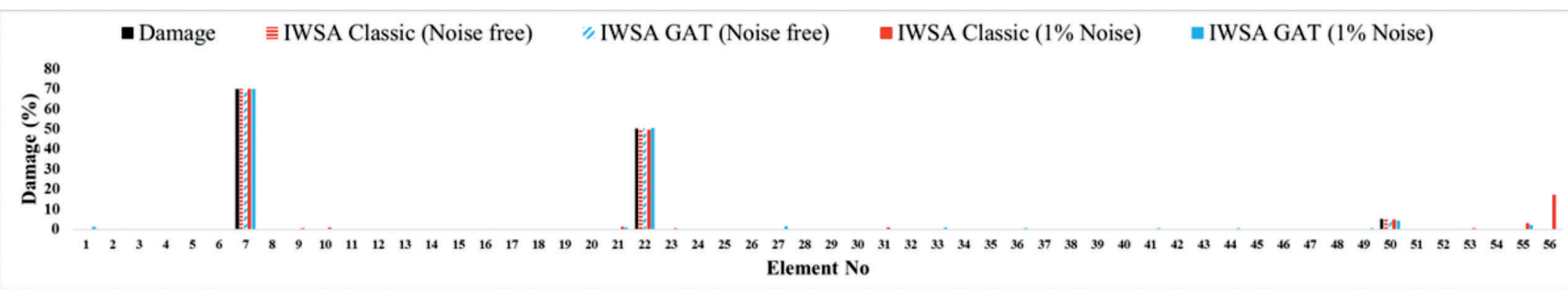

(a)

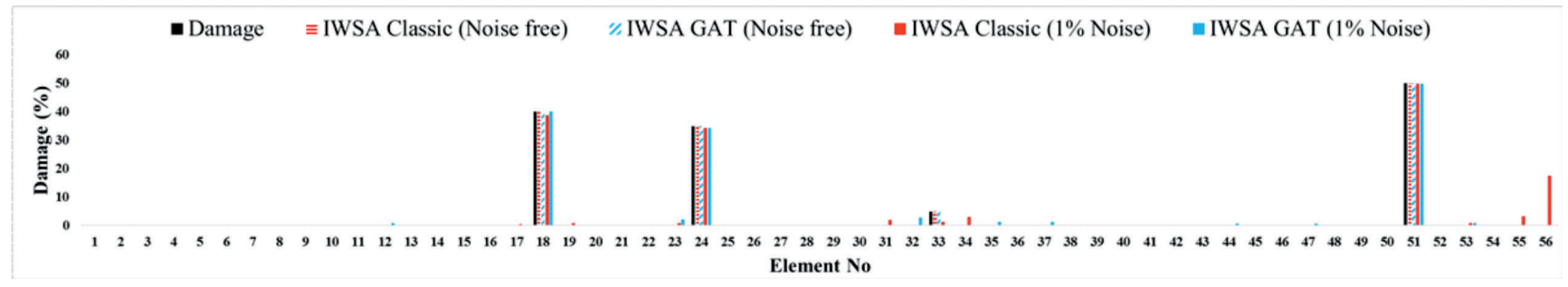

(b)

Fig. 15 The best detections obtained by the IWSA algorithm for the concrete portal frame structure

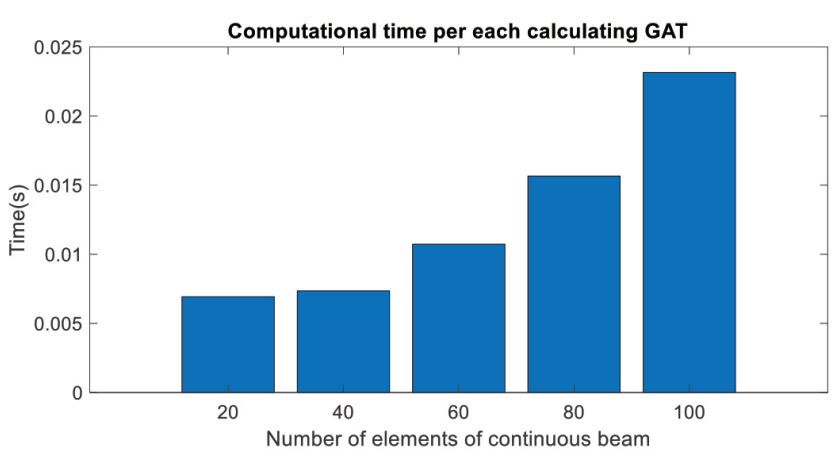

(a)

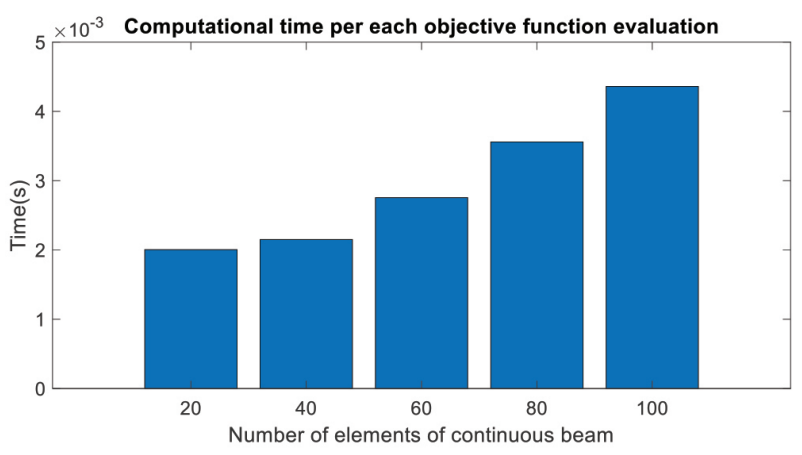

(b)

Fig. 16 Computational time per (a) calculating GAT (b) each objective function evaluation 


\section{References}

[1] Chan, T. H. T., Li, J., Caprani, C. "Structural identification and evaluation for SHM applications", Journal of Civil Structural Health Monitoring, 8(5), pp. 719-720, 2018. https://doi.org/10.1007/s13349-018-0308-1

[2] Das, S., Saha, P., Patro, S. K. "Vibration-based damage detection techniques used for health monitoring of structures: a review", Journal of Civil Structural Health Monitoring, 6(3), pp. 477-507, 2016. https://doi.org/10.1007/s13349-016-0168-5

[3] Deák, F., Kovács, L., Mucsi, P., Máthé, Z. "Microscopic Identification of Progressive Fracturing in Granite Under Triaxial and Uniaxial Stress Conditions from Bátaapáti Radwaste Repository", Periodica Polytechnica Civil Engineering, 64(1), pp. 231-240, 2020. https://doi.org/10.3311/PPci.15287

[4] Rytter, A. "Vibrational based inspection of civil engineering structures", PhD Thesis, University of Aalborg, 1993.

[5] Friswell, M. I. "Damage identification using inverse methods", Philosophical Transactions of the Royal Society A: Mathematical, Physical and Engineering Sciences, 365(1851), pp. 393-410, 2007.

[6] Wolpert, D. H., Macready, W. G. "No free lunch theorems for optimization", IEEE Transactions on Evolutionary Computation, 1(1), pp. 67-82, 1997.

https://doi.org/10.1109/4235.585893

[7] Azimi, M., Pekcan, G. "Structural health monitoring using extremely compressed data through deep learning", Computer-Aided Civil and Infrastructure Engineering, 35(6), pp. 597-614, 2020.

https://doi.org/10.1111/mice.12517

[8] Li, W.-M., Hong, J.-Z. "Research on the iterative method for model updating based on the frequency response function", Acta Mechanica Sinica, 28(2), pp. 450-457, 2012. https://doi.org/10.1007/s10409-012-0063-1

[9] Chou, J.-H., Ghaboussi, J. "Genetic algorithm in structural damage detection", Computers \& Structures, 79(14), pp. 1335-1353, 2001.

[10] Boonlong, K. "Vibration-Based Damage Detection in Beams by Cooperative Coevolutionary Genetic Algorithm", Advances in Mechanical Engineering 6, Article ID 624949, 2014. https://doi.org/10.1155/2014/624949

[11] Majumdar, A., Maiti, D. K., Maity, D. "Damage assessment of truss structures from changes in natural frequencies using ant colony optimization", Applied Mathematics and Computation, 218(19), pp. 9759-9772, 2012.

https://doi.org/10.1016/j.amc.2012.03.031

[12] Cha, Y.-J., Buyukozturk, O. "Structural Damage Detection Using Modal Strain Energy and Hybrid Multiobjective Optimization", Computer-Aided Civil and Infrastructure Engineering, 30(5), pp. 347-358, 2015.

https://doi.org/10.1111/mice.12122

[13] Tan, Z. X., Thambiratnam, D. P., Chan, T. H. T., Gordan, M., Abdul Razak, H. "Damage detection in steel-concrete composite bridge using vibration characteristics and artificial neural network", Structure and Infrastructure Engineering, 16(9), pp. 1247-1261, 2020.

https://doi.org/10.1080/15732479.2019.1696378
[14] Kang, F., Li, J., Xu, Q. "Damage detection based on improved particle swarm optimization using vibration data", Applied Soft Computing, 12(8), pp. 2329-2335, 2012.

https://doi.org/10.1016/j.asoc.2012.03.050

[15] Seyedpoor, S. M. "A two stage method for structural damage detection using a modal strain energy based index and particle swarm optimization", International Journal of Non-Linear Mechanics, 47(1), pp. 1-8, 2012. https://doi.org/10.1016/j.ijnonlinmec.2011.07.011

[16] Kaveh, A., Zolghadr, A. "Guided Modal Strain Energy-Based Approach for Structural Damage Identification Using Tug-ofWar Optimization Algorithm", Journal of Computing in Civil Engineering, 31(4), Article No.04017016, 2017. https://doi.org/10.1061/(ASCE)CP.1943-5487.0000665

[17] Kaveh, A., Dadras Eslamlou, A. "Metaheuristic Optimization Algorithms in Civil Engineering: New Applications", Springer, Cham, Switzerland, 2020. https://doi.org/10.1007/978-3-030-45473-9

[18] Kaveh, A., Dadras Eslamlou, A., Khodadadi, N. "Dynamic Water Strider Algorithm for Optimal Design of Skeletal Structures", Periodica Polytechnica Civil Engineering, 64(3), pp. 904-916, 2020. https://doi.org/10.3311/PPci.16401

[19] Kaveh, A., Dadras, A. "Structural damage identification using an enhanced thermal exchange optimization algorithm", Engineering Optimization, 50(3), pp. 430-451, 2018. https://doi.org/10.1080/0305215X.2017.1318872

[20] Fan, W., Qiao, P. "Vibration-based Damage Identification Methods: A Review and Comparative Study", Structural Health Monitoring, 10(1), pp. 83-111, 2011. https://doi.org/10.1177/1475921710365419

[21] Friswell, M. I., Penny, J. E. T., Garvey, S. D. "A combined genetic and eigensensitivity algorithm for the location of damage in structure", Computers \& Structures, 69(5), pp. 547-556, 1998. https://doi.org/https://doi.org/10.1016/S0045-7949(98)00125-4

[22] Bathe, K.-J., Wilson, E. L. "Solution methods for eigenvalue problems in structural mechanics", International Journal for Numerical Methods in Engineering, 6(2), pp. 213-226, 1973. https://doi.org/10.1002/nme.1620060207

[23] Yuan, Y.-X., Dai, H. "A generalized inverse eigenvalue problem in structural dynamic model updating", Journal of Computational and Applied Mathematics, 226(1), pp. 42-49, 2009. https://doi.org/https://doi.org/10.1016/j.cam.2008.05.015

[24] Verma, R., Roy, N., Ganguli, R. "Gas turbine diagnostics using a soft computing approach", Applied Mathematics and Computation, 172, pp. 1342-1363, 2006. https://doi.org/10.1016/j.amc.2005.02.057

[25] Kaveh, A., Dadras Eslamlou, A. "Water strider algorithm: A new metaheuristic and applications", Structures, 25, pp. 520-541, 2020. https://doi.org/10.1016/j.istruc.2020.03.033

[26] Kaveh, A., Rahmani, P. "Canonical forms and rotationally repetitive matrices for eigensolution of symmetric structures", Scientia Iranica, 28(1), pp. 192-208, 2020. https://doi.org/10.24200/sci.2020.56639.4827 
[27] Kaveh, A., Rahami, H., Shojaei, I. "Swift Analysis of Civil Engineering Structures Using Graph Theory Methods", Springer, Cham, Switzerland, 2020.

https://doi.org/10.1007/978-3-030-45549-1

[28] Kaveh, A., Roosta, G. R. "Graph-theoretical Methods for Substructuring, Subdomaining and Ordering", International Journal of Space Structures, 10(2), pp. 121-131, 1995. https://doi.org/10.1177/026635119501000205

[29] Giger, M., Ermanni, P. "Evolutionary truss topology optimization using a graph-based parameterization concept", Structural and Multidisciplinary Optimization, 32(4), pp. 313-326, 2006. https://doi.org/10.1007/s00158-006-0028-8

[30] Kaveh, A., Rahmani, P., Dadras Eslamlou, A. "A Multistage Damage Detection Approach Using Graph Theory and Water Strider Algorithm", Iranian Journal of Science and Technology, Transactions of Civil Engineering, 2021. https://oi.org/10.1007/s40996-020-00578-4

[31] Kaveh, A., Dadras Eslamlou, A. "An efficient two-stage method for optimal sensor placement using graph-theoretical partitioning and evolutionary algorithms", Structural Control and Health Monitoring, 26(4), Article ID e2325, 2019. https://doi.org/10.1002/stc.2325

[32] Zhou, R., Hansen, E. A. "Breadth-first heuristic search", Artificial Intelligence, 170(4-5), pp. 385-408, 2006. https://doi.org/10.1016/j.artint.2005.12.002

[33] Sniedovich, M. "Dijkstra's algorithm revisited: the dynamic programming connexion", Control and Cybernetics, 35(3), pp. 599620, 2006.

[34] Holland, J. "Genetic Algorithms", Scientific American, 267, pp. 66-73, 1992.

[35] Kennedy, J., Eberhart, R. "Particle swarm optimization", In: Proceedings of ICNN'95-International Conference on Neural Networks, Perth, WA, Australia, 1995, pp. 1942-1948. https://doi.org/10.1109/ICNN.1995.488968
[36] Atashpaz-Gargari, E., Lucas, C. "Imperialist competitive algorithm: an algorithm for optimization inspired by imperialistic competition", In: IEEE Congress on Evolutionary Computation, Singapore, 2007, pp. 4661-4667. https://doi.org/10.1109/CEC.2007.4425083

[37] Mirjalili, S. "Moth-flame optimization algorithm: A novel nature-inspired heuristic paradigm", Knowledge-Based Systems, 89, pp. 228-249, 2015. https://doi.org/10.1016/j.knosys.2015.07.006

[38] Mirjalili, S., Mirjalili, S. M., Lewis, A. "Grey Wolf Optimizer", Advances in Engineering Software, 69, pp. 46-61, 2014. https://doi.org/10.1016/j.advengsoft.2013.12.007

[39] Sadollah, A., Sayyaadi, H., Yadav, A. "A dynamic metaheuristic optimization model inspired by biological nervous systems: Neural network algorithm", Applied Soft Computing, 71, pp. 7477822018 https://doi.org/10.1016/j.asoc.2018.07.039

[40] Kaveh, A., Mahdavi, V. R. "Colliding bodies optimization: A novel meta-heuristic method", Computers \& Structures, 139, pp. 18-27, 2014.

https://doi.org/10.1016/j.compstruc.2014.04.005

[41] Heidari, A. A., Mirjalili, S., Faris, H., Aljarah, I., Mafarja, M., Chen, H. "Harris hawks optimization: Algorithm and applications", Future Generation Computer Systems, 97, pp. 849-872, 2019. https://doi.org/10.1016/j.future.2019.02.028

[42] Kaveh, A., Rahmani, P., Dadras Eslamlou, A. "Guided Water Strider Algorithm for Structural Damage Detection Using Incomplete Modal Data", Iranian Journal of Science and Technology, Transactions of Civil Engineering, 2021. https://oi.org/10.1007/s40996-020-00552-0 